\title{
Determinants of Childhood Routine Immunization Coverage in Sokoto State, North West Nigeria.
}

\author{
Usman Tijjani \\ Consultant of Monitoring, Evaluation \& Learning (MEL) of Public Health Programs \\ Email Address: tijjaniusman100@gmail.com \\ Address: No.8, Guava Road, Unguwan Dosa, Kaduna \\ City: Kaduna \\ Country: Nigeria - North West Nigeria \\ Zip Code: +23401
}

DOI: 10.31364/SCIRJ/v8.i8.2020.P0820797

http://dx.doi.org/10.31364/SCIRJ/v8.i8.2020.P0820797

\begin{abstract}
Routine immunization contributes significantly in the reduction of childhood mortality among children through vaccination against preventable diseases in Nigeria, (WH0,2017). This study seeks to assess the determinants of Childhood Routine Immunization coverage in Sokoto State. Findings from the research study indicates that routine immunization coverage is still very low in Sokoto State when compared with the national target of $80 \%$ coverage (RI Strategic Plan 2013-2015). Also, this research discovered that about half of the children in Sokoto State, Nigeria are partially or not immunized at all. This clearly indicates that about half of children born in Sokoto State have not received pentavalent vaccine by the time they reach their first birthday. The challenges of immunization coverage in Sokoto State is attributed to Mothers/Caregivers inability to take their child to the health facility, unaware of immunization schedule, unaware of immunization need, absence of vaccinators, forgetfulness, no need felt, fear of AEFI, unaware of place and time, no faith/belief in immunization, lack of vaccines at the health facilities. The study recommends that government should make an extra effort to sensitize caregivers and counseled them on the significance of taking their children to health facilities for vaccination.
\end{abstract}

Keywords: Sub Saharan Africa, North west Nigeria, Sokoto State, coverage, routine immunization, routine immunization schedule, routine immunization coverage, vaccines, prevalence, determinants of routine immunization.

\subsection{INTRODUCTION}

According to World Health Organization (WHO) "Routine immunization (RI) is the sustainable, reliable and timely interaction between the vaccine, those who deliver it and those who receive it to ensure every person is fully immunized against vaccine-preventable diseases", (WHO, 2017). Immunization is considered important for improving child survival (Lee, 2005). WHO (2017), recommended that vaccines must be administered to each child during the first year of life of the child within the specified immunization schedule? The recommendation made by WHO is aimed at reducing individual vulnerability and prevent the recurrence of outbreak of the diseases within communities, (Wiysonge C.S. et al. 2012).

The continent of Africa has the highest number of underfive mortality rate in the world, $40 \%$ of these deaths are occurring in sub Saharan Africa and the major contributors to these number of mortalities is as a result of vaccine preventable diseases, (Wiysonge C.S. et al. 2012). Most of these children die because they do not have access to effective preventive routine immunization intervention that would help in fighting common and preventable childhood diseases, (WHO, 2007). In the year 2010, a total number of six million children in SubSaharan Africa did not receive diphtheria-tetanus-pertussis(DTP-3), (Wiysonge C.S. et al. 2012). A report by WHO, stated that 10 countries from Sub Saharan Africa are host to $60 \%$ of children that were not reached with routine immunization services, (WHO, 2017). At the global level, facts have shown that about 9 million death of children that happened globally as a result of vaccine preventable disease, 4.4 million is from Sub Saharan Africa and this figure is largely attributed to inadequate immunization coverage in the region, (Asrat Meleko et al. 2017). As a result of lack of inadequate immunization, an estimated number of 527,000 children most of whom are from low-income countries die each and every year from vaccine preventable rotavirus infections alone, (WHO, 2015).

As a result of RI, about 2-3 million lives were saved worldwide on a yearly basis through immunization programs, (UNICEF, 2018). Immunization alone has made significant contribution to public health through elimination, eradication and control of life-threatening diseases in African region, (Mihigo R., et. al, 2017). In view of the fact that the available global vaccine can avert an estimated $25 \%$ number of death of children, the World Health Organization (WHO), the United Nations Children Funds (UNICEF), developed what is a called Global Immunization Vision and Strategy with the sole objectives of increasing the number of children being 
immunized against vaccine preventable diseases globally, (Adedokun et al., 2017).

In trying to pursue the goal of ensuring each and every child is protected against vaccine preventable disease, the WHO lunched an expanded program on immunization (EPI) in the year 1974 which the Nigerian government also initiated in the year 1979, (Saheed Gidado et al. 2014). After the initiation of the EPI program in Nigeria, the intervention of the program brought about an increase in immunization coverage in the entire country for a certain period of time, the government had to revitalized the EPI program with renewed government ownership and oversight in the year 1996 so that the coverage can be increased but surveys conducted in the year 2003 and 2006 clearly indicated that all the antigens in the country was still below 50\%, (Saheed Gidado et al. 2014). The EPI programs in Nigeria has eight vaccine preventable diseases namely: tuberculosis, measles, poliomyelitis, whooping cough, diphtheria, tetanus HepB and Hib known as EPI program disease, (Adebiyi F. 2013). The goal of the EPI program is to make sure each and every child received protection against vaccine preventable diseases by one (1) year of age, (Saheed Gidado et al. 2014).

At the initial period when the EPI program was initiated and commenced operation in the year 1979, Nigeria immediately started witnessing a tremendous increase in immunization coverage from the year 1980 which is a year after the commencement of the EPI program, and this lasted to the year 1990 and immediately thereafter the country has been witnessing a decline in the immunization coverage mostly due to failure of the primary health care system and lack of full commitment by the government, (Salako A. A., et al., 2009). Contrary to the conditions of poor routine immunization coverage in Nigeria, Nigeria like many other African countries is making extra efforts to strengthen its entire health system most especially in the areas of routine immunization so as to reduce the burden from vaccine preventable diseases, (Adeyinka D.A. et al 2009).

Findings of the Nigeria Multiple Indicator Cluster Survey MICS (2017) placed Nigeria immunization coverage at 33\%, which means only $33 \%$ of children received pentavalent vaccine by the time they reach their first birthday. Out of the 36 states in Nigeria, Sokoto State is having the worst immunization coverage which stand at just $3 \%$. The immunization coverage in Nigeria is too low for controlling vaccine preventable diseases (Brown V.B., et., al 2017). Vaccine preventable diseases alone in Nigeria attributed to about $22 \%$ of childhood deaths amounting to about 200,000 deaths per year (Adedire E.B., et al., 2016). Based on these findings USAID (2018) stated that "Immunization coverage rates in Nigeria is among the lowest and most inequitable in the world", Despite the calls by the world health assembly which calls on all countries to reach $\geqslant 90 \%$ national coverage with all vaccines in the country' s national immunization schedule by 2020 as contained in the Global Vaccine Action Plan 2011 2020.

Findings of the MICS 2017 survey has clearly shown that in all the six geo-political zones in Nigeria, North West Nigeria, has the worst Immunization coverage. A research finding by Sule Abdullahi (2018), revealed that North West Region of Nigeria has the lowest immunization coverage which stands at $10 \%$, while both South East and South West region had $52 \%$ coverage of children immunized. Challenges of trained health personnel, attitude of health workers/managers, shortage of vaccine and supplies to the health facilities, mistrust or fear, insecurity in some areas, poor quality health information system data at the service delivery point, are the reasons behind difficulty in planning and delivery of quality services to children in need of immunization services in Nigeria, (Dr. F. Shuaib 2017, USAID 2018). Although the Nigerian health care system has its own peculiar characterizing and these peculiarities are related to her religious, cultural and socio-political diversities, (Alenoghena, I., et al. 2014). Kaoje et al (2017), revealed that the socio-cultural factors found to affect the acceptance of routine immunization services by mothers/caregivers includes place of delivery, educational level and the occupation of the parents of the children. Sometimes back in the year 2003, political and religious leaders in northern Nigeria stopped the immunization campaigns by calling parents not to allow their children to be immunized because of the argument that the vaccine could be contaminated with HIV, anti-infertility agents and cancerous agents, (Jegede A.S. 2007).

In Nigeria, Routine Immunization (RI) is one of the key elements of primary health care, a first level of contact of families, individuals and communities with the national health care system, (Alenoghena, I., et al. 2014). The Primary Health Care Centers are managed by the National Primary Health Care Development Agency at the national level while at the state and local government area, the primary health care centers are managed by the State Primary Health Care Development Agencies. The Nigerian Government established the Primary Health Care Agency with the responsibility of mobilizing support for PHC program implementation both nationally and internationally, (FMOHN, 2004). In spite of the implementation of the primary health care plan which was designed to help improve immunization rates in Nigeria, immunization coverage still remains very low, (Ngowu, R., 2008). Immunization services in Nigeria are conducted through two main strategies namely routine immunization (RI) and Supplemental Immunization Activities (SIA). Routine immunization is the consistent delivery of immunization services to infants through the administration of vaccines based on a schedule, (Saheed Gidado et al. 2014). The immunization schedule in Nigeria, prescribed five visits to each child born to receive one dose of Bacille Calmette Guerin (BCG), four doses of oral polio vaccine, three doses of diphtheria, pertussis and tetanus vaccine, and one dose of measles vaccine, (FMOHN, 2004). In Nigeria routine immunization schedule states that immunization services should be given to children starting from birth and to be completed before one year of life by all children, (Funmilayo Adebiyi 2013)

In the year 2017, same year the MICS survey was conducted and disseminated, about 60 to $70 \%$ of children under one year of age in Nigeria are not reached out for routine immunization according to the (WHO 2017). The similarities between the WHO report and the MICS survey report which was conducted in the same year 2017 are almost the same. About 1,000 children died in 2017 in northern Nigeria from vaccine preventable disease according to Owoseye A., (2018). At the same period, a total number of 14,513 cases of meningitis were also reported out of which 1,116 children died as a result of the outbreak according to Owoseye A., (2018) of premium times newspapers. This is about $8 \%$ mortality based on the figures reported. In addition, there was also outbreak of 
cholera in northern Nigeria in which 1,558 cases were reported and there was a mortality of about 11 children as a result of the outbreak within the same period in the year 2017. Sokoto State with the worst immunization coverage in Nigeria based on the MICS survey findings which stand at 3\%, has the second highest number of cases and mortalities during the outbreak according to, (Owoseye A., 2018).

Due to the performance of Sokoto State during the MICS 2017 survey, the state was identified as one of the worst performing states in Nigeria in terms of immunization coverage by the National Primary Health Care Development Agency (NPHCDA). These are enough facts and evidence to make this a public health issue that needs the attention of all stakeholders e.g. Government, community and religious/community leaders and international partners e.g. WHO, USAID, UNICEF, BMGF etc. However, findings based on the MICS 2017 report necessitated the need to find out the actual determinants of Childhood Routine Immunization Coverage in Sokoto State because of its relevance and importance in safe guading the lives of children who are born and entitle to be immunized by the government and to cut down the number of children who are dying daily as a result of vaccine preventable disease in Sokoto State, North West Nigeria. Low immunization coverage in Sokoto State which stand at only $3 \%$ is enough public health issue that needs the attention of the government and is the actual reason why this research study is been conducted. This research is very necessary to inform intervention and program management in Sokoto state and northern Nigeria as a whole.

However, this research study will help policy makers, health workers, community leaders, donor agencies to understand the actual determinants of routine immunization and also be a guide for effective utilization of resources and evidence-based recommendations for addressing the challenges of routine immunization coverage in Sokoto State.

\subsection{BACKGROUND INFORMATION}

Regardless of the endowment of abundant resources both human and natural that Nigeria is blessed with, childhood mortality is still extremely high, (Sule Abdullahi 2018). The Nigerian government tried in the implementation of a primary health care plan through the National Primary Health Care Development Agency and its states and Local Government Area offices designed to help improve immunization rates in the country but still immunization coverage remains very low, (Ngowu 2008). With over 200 million population of people and $4 \%$ of this population under one year of age, only $33 \%$ of children under one of age were covered during the last MICS 2017 survey, this figure is among the lowest immunization coverage in the world (NPoPC, MICS 2017). It is sad that $40 \%$ of these children visited during the MICS 2017 survey did not receive any vaccines from the health system as found during the MICS survey according to the, MICS Survey Brief (2017).

Immunization seems to be the highly effective public health intervention that has the strength to extremely reduce child mortality from vaccine preventable disease in developing countries, (WHO, 2009). Previous research work findings have found that Knowledge and education status of mother/caregivers, educating mothers/caregivers and increasing their literacy level are very essential to advance immunization coverage because children from mothers/caregivers with higher level of education have significantly higher rates completed basic vaccinations, (Funmilayo, 2013; Saleena et al., 2014; Gidado et al., 2014).

\subsection{IMMUNIZATION COVERAGE IN NigERIA AND IN SOKOTO STATE}

Based on the Multi Cluster Survey report findings, Nigeria has $33 \%$ Immunization coverage and Sokoto State has the lowest immunization coverage among all the 36 States in Nigeria which stands at only $3 \%$, this immunization coverage placed Nigeria as one of the countries with low immunization coverage in the world and Sokoto State with the worst immunization coverage among the 36 states in Nigeria, (MICS, 2017, USAID, 2018). Although, this is a survey finding but even the administrative data based on the revisited EPI program shows Immunization coverage in the year 1999 stand at $17 \%$ coverage, 2003 at $13 \%$ and 2008 at $23 \%$ ), these figures are by far below the National coverage of $80 \%$ (NPI, 1999; 2008; RI Strategic Plan 2013-2015). The low immunization coverage in Nigeria could be attributed to low political will from the side of the government, lack of funding, poor social support, poor community involvement and participation, ethnicity and religious beliefs. (Funmilayo, 2013; Ophori E.A. et al., 2014).

This research explores the knowledge and attitude of mother/caregivers about determinants and prevalence of routine vaccination among children 0-11 months of age in Sokoto State and the research question is: "What is the prevalence of routine vaccination among children and what are the determinants of childhood vaccination in Sokoto State, North West Nigeria"?

\subsection{OBJECTIVES}

The main objective of this study is to assess the determinants of Childhood Routine Immunization coverage in Sokoto State. The specific objectives of these study are to:

1. Review the literature on childhood vaccination and its determinants.

2. Estimate the RI vaccination coverage for routine individual vaccines and full vaccination for children 0-11 months' old.

3. Investigate determinants of vaccination in Sokoto State

\subsection{LITERATURE REVIEW}

The aim of this literature review is to provide a foundation of knowledge based on the research topic, identify certain areas of previous scholarship, to prevent duplication of work, to give credit to other researchers who have done a similar work sometimes back and to open up need for additional research. The objective of this literature review is to review literatures on childhood vaccination and its determinants across the globe 
with special interest in Sub Saharan Africa and Nigeria in particular.

\subsection{LITERATURE REVIEW STRATEGY}

During the course of writing this literature review, a total number of about sixty-seven (67) different websites were visited. These websites are those of the United Nations (UN), United States Agency for International Development (USAID), World Health Organization (WHO), United Nations Children and Education Fund (UNICEF), Centre for Disease Control and Prevention (CDC), Millennium Development Goals (MDGs), etc. Google Scholar Search engine was also used during the course of searching for articles in writing this literature review. Additional articles were also sourced from local sources which deal with coverage and determinants of routine immunization. These articles and publication were found on the websites of the Federal Ministry of Health (FMOHN), National Primary Health Development Agency (NPHCDA), National Population Commission (NPoPC), Premium Times Newspapers Nigeria etc. Different categories of databases were also used in the search for literatures such as EBSCOhost, BMJ journals, BMC public Health, PUBMED, Elsevier, PanAfrican Medical Journal, Internet Scientific Publications, and ResearchGate.

A total number of sixty-three (63) research papers/articles, journals were initially selected but only twenty-nine (29) of the research papers/articles met up the inclusion criteria. The inclusion criteria include: the journals/articles most be in the areas of routine immunization, the articles/journals reviewed and used must be published within the past 10 years but only few were more than 10 years which were included to give some historical background on routine immunization coverage and also determinants and prevalence of routine immunization in Nigeria and to demonstrate the rareness of literatures on local based research studies at the community level, particularly in North west Nigeria. All in all, at the end, a total number of twenty-nine (29) research papers/articles were used.

\subsection{THE DETERMINANCIES OF THE IMMUNIZATION}

Regardless of the significant drop in child mortality even among poor income countries in Sub Saharan Africa, there is no any significant change, and the entire African country is home to about $41 \%$ of the estimated number of 10.8 million children who die yearly globally as a result of vaccine preventable disease as found in one of the research work conducted by Sule Abdullahi (2018). The under-five mortality which was crowned as the leading indicator of child health in Sub Saharan Africa was incorporated into MDGs goal with the sole aim of reducing death rate by two-thirds between the year 1990 and 2015, (Adegboye O.A., et al., 2013). Based on the MDG's goal of "Reducing Child Mortality", Sub Saharan Africa has the highest child mortality in the world although the under-five mortality rate within the same Sub Saharan Africa region has fallen from 179 deaths per 1,00 live births in the year 1990 to 86 in the year 2015, (MDGs report, 2015). In one of the research by Mihigo R., et al., (2017) on the challenges of immunization in Africa, the researchers found out that immunization coverage for Africa as a whole has raised from $57 \%$ in the year 2000 to about $76 \%$ in the year 2015 but unfortunately the figures still remained below the expected global expected target of $\geq 90 \%$ according to (WHO 2012). Although there are reasons behind the low immunization coverage which Machingaidze A., (2013) also found out in his research findings as: the quality of immunization data in many African countries are questionable. Some of the reasons that made immunization data which is actually used in calculating the immunization coverage in African countries questionable are inconsistencies in reported data which automatically makes data monitoring in most African countries to be weak, (Machingaidze S., 2013).

There are some previous research studies that have investigated the determinants and prevalence of routine immunization coverage in Africa, Sub-Saharan Africa and Nigeria. In Africa, the factors leading to immunization coverage disparities are generally not well understood by many individuals because the quality of immunization data in many of these African countries are doubtful, only some very few research studies are asking why immunization coverage has improved in some locations and not others (Gauri V., et al. 2002). Identifying key factors associated with high or low immunization coverage, difficulties with immunization programs and obstacles to obtaining immunizations are the most common approaches to assessing the performance of immunization systems in African region, (LaFond A., et al 2015). However, the idea of improving the benefits of immunization by accomplishing high immunization coverage has met with many challenges (Mihigo R., et al., 2017). Some of these challenges as stated by Mihigo R., et al., (2017) are issues with sustainable funding, data quality issues, lack of enough resources for immunization, vaccine stock-outs and logistics. Some similar research studies that were conducted in other sub Saharan Africa countries and Nigeria in particular gave similar challenges facing immunization in the region and Nigeria as well. For example, in one of the research works conducted by Wiysonge C.S. et al. (2012), stated that, there is limited data showing childhood immunization programs in sub-saharan Africa.

In Nigeria for instance, the determinants of routine immunization in northern Nigeria is similar in nature in most of the states across the region. For example, religion, attitude and cultural believes of parent of children have been identified as some of the challenges why parents do not take their children for routine immunization services, (Kabir M., et al., 2005). This finding was based on a research finding on "Knowledge, perception and beliefs of mothers on routine childhood immunization in a Northern Nigerian Village" by 
Kabir M., et al., (2005). Just like a mere coincidence, similar finding was made by USAID on the status of routine immunization in northern Nigeria in the year 2018 which revealed that attitude; lack of education and awareness; culture and religion are the major challenges facing routine immunization in northern Nigeria. In a similar manner, another research study conducted in Zamfara State, North West Nigeria, stated that mother's/caregiver's knowledge and educational status as among the major factors influencing immunization coverage in the region, (Saheed Gidado et al. 2014). These are some of the reasons why mothers/caregivers of children do not take their children for routine immunization services based on the findings of some of the research work that were conducted earlier.

Individual, community and state level factors etc. were among the factors that made children to have an incomplete immunization in Nigeria and these are mothers/caregivers that are illiterate, mothers or caregivers who did not attend anti natal clinics during pregnancy, mothers/caregivers who delivered at home, mothers/caregivers of children who lived in rural areas, mothers/caregivers who had difficulty getting to health facility, were more likely to have children that are incompletely immunized, (Adedokun T. et al., 2019). Findings of a research work conducted by Adedokun T. et al., (2019) on "Incomplete childhood immunization in Nigeria" revealed that one quarter of the deaths as a result of vaccine preventable diseases are preventable through interventions like immunization. Distance from communities to health facilities is another finding made by Adebiyi F. (2013), who also found that distance from communities where the mother's/caregivers stay to the health facilities is another big reason why children are not fully immunized in Nigeria. The issue of distance to health facility also affects immunization coverage in Kenya according to Ndiritu et al., (2006). While Reichler et al., (1998) in his research found that closeness to health facilities is heavenly associated with an increased in immunization coverage in Egypt. A research study in Kenya found mothers/caregivers who attend Anti Natal Clinics and at the same time give birth at the health facilities are more likely to have their children immunized as the venue of the ANC visits are also spot for providing awareness on the relevance of immunization programs to mother/caregivers, (Mutua et al., 2011). In Nigeria, $65.7 \%$ of mothers/caregivers got awareness about immunization at the ANC clinic as found by Adedayo et al., (2009). However, a research study conducted in Niger Delta area of Nigeria by Oku A., et al, (2017), discovered that there was a great relationship between a Childs place of delivery and the immunization status of that child.

Another cross-sectional study by Gidado S., et al (2010) conducted in north west Nigeria found that only $44 \%$ of mothers/caregivers knew the right purpose of childhood immunization, (Gidado S., et al. 2010). This finding clearly shows lack of awareness on the mother's/caregiver's side who are supposed to be very much aware of the relevance of immunization of their children. Some of the research findings have reported that mothers/caregivers have good knowledge of immunization and vaccine preventable diseases e.g. one of the findings by Adedire E.B., et al., (2016), $76 \%$ of mothers/caregivers have a good knowledge of routine immunization and vaccine preventable diseases. This research finding is telling us that more mothers/caregivers have a good knowledge of immunization and vaccine preventable diseases. A similar cross-sectional research finding conducted by Odusanya et., al (2008), found that $87 \%$ of mothers/caregivers have a satisfactory level of knowledge about routine immunization in northern Nigeria. According to Caldwell, J. (1979), the education of mothers/caregivers is an important determinant of child health and there is no any other factor that has such an impact. Lack of understanding the relevance of high-quality data for decision making by the service providers, over dependence on administrative coverage report, heavy workload by the service providers are the main reasons of poor-quality data that is seriously affecting routine immunization coverage in Nigeria according to Omoleke et al., (2017). Another big factor affecting immunization coverage is ignorance and social cost of having access to immunization services for some of the mothers/caregivers of children as stated by Oluwadare C., (2017). This is a research study that was conducted in southwest Nigeria. With all these findings put in place, Jegede A.S. (2007), stated that influence of religious and political leaders in Nigeria, has made mothers/caregivers not to immunize their children because of the believe that the vaccines for immunization are contaminated with HIV, anti-fertility and cancerous agents Jegede A.S. (2007).

According to D'Onofrio et al, (2010), the determinants of childhood immunization still remain complex and these determinants are dependent on various supply and demand factors, socio-economic and demographic factors etc. Other researchers like Harvey, P.A.M. (2014) and Tagbo, B.N., et al. (2013), have also revealed that, there are several factors that have been implicated as mitigating factors of low vaccination coverage in low income countries like Nigeria and these factors are cultural and religious believes, lack of political will, attitude of health workers, misconception about safety of vaccines etc. Adeyinka D.A. et al (2009), revealed in his research study that perception, beliefs and practices towards measles and measles vaccination showed 1 of 500 mothers interviewed believed that measles is prevented by immunization in northern Nigeria, $16 \%$ believed that it is contagious, $25 \%$ have never heard of measles immunization, $26 \%$ believed that it is caused by evil spirit and witch craft, $27 \%$ said they did not believe that immunization was effective.

However, the issue of supply related factors is also very important and cannot be left out according to Jheeta M., et al, (2008), who stated that adequate supply of vaccines cannot certainly translate into children being vaccinated emphasizing 
the requirement to eliminate the unavoidable inequities that are associated with norms and structural factor that may deter increased vaccination uptake, (Jheeta M., et al, 2008). There is an urgent need to educate parents of children about vaccine preventable diseases as well as the importance of such vaccines themselves as one of the ways to impact the significance of vaccine to the health of their children, (Abdulraheem I. S. et al., 2011). There is also need for Nigeria to copy the Senegal example by bringing in technology into the system to ensure every child is reach out for immunization services, Senegal in West Africa has managed to increased its immunization coverage from $51 \%$ to $91 \%$ due to technology innovation, (UNICEF, 2008).

In Summary, this study lures some existing literatures to identify the actual prevalence and determinants of routine immunization in Sokoto State using the state Load Quality Assurance Survey (RI LQAS, 2018) data. Findings based on the RI LQAS 2018 data has shown that the frequency for Gender Distribution of Children Male (50.9\%) and for Female $(49.1 \%)$ while the frequency of distribution of children not immunized by Gender is (45.2 Male) and (54.8\% Female). About one-third of children surveyed are between age 4-8 month. The figures also show that about $20 \%$ of children in Sokoto State have never received any vaccine and only $50.9 \%$ of children are fully immunized which is below the national coverage of $80 \%$ (RI Strategic Plan 2013-2015). By these findings, this research study expects to make significant contribution by contributing to existing knowledge on the increase of child immunization coverage in Nigeria, inform government policies and programs in Nigeria towards improving routine immunization coverage.

\subsection{RESEACH METHOLOGY}

This research study is a cross sectional study and also quantitative research work by design. A cross sectional study is relevant method for this research study because it is one of the research methods that has the capability of assessing the proportion of individuals both children or adult with disease or risk factors for diseases, (Lorraine K. et al., 2014). This research work is embracing cross sectional research method because it intends to critically find out the prevalence of routine vaccination among children of 0-11 months of age and also find out the determinants of childhood vaccination of children in Sokoto State, north west Nigeria.

The data for this research work was obtained from the Nigeria National Routine Immunization Load Quality Assurance Sampling (RI LQAS) database which is carried out every quarter since late 2017 in 18 identified worst performing states in Nigeria. The data for four cycles (Q1, Q2, Q3 Q4) of the 2018 RI LQAS for Sokoto State was used in this research study. Each cycle of the LQAS is been conducted after every three (3) months which makes it a quarterly affair. The age for the children for this study is between the age bracket of 0-11 months. This is because the routine immunization vaccines are ordinary supposed to be administered between $0-11$ months of child delivery, (WHO, 2005). Based on the recommendation of World Health Organization (WHO), vaccines must be administered during the first year of life of a child within a specified schedule.

Analysis is presented to show the trend of RI coverage and its determinants in Sokoto state within the time frame of the survey. A total of 1,380 caregivers were interviewed in each Quarter. Also, equal number of respondents (60) was sampled in each of the 23 LGAs in each quarter. Mothers/caregivers of children 0-11 months of age were interviewed during the conduct of the LQAS survey. Routine Immunization vaccination card and history of their children vaccination was used by the mothers/caregivers as an evidence during the conduct of the assessment. As an evidence, each of the immunization cards presented by the mother/caregivers during the conduct of the assessment has to be linked to the health facility were the immunization took place to ascertain authenticity of the vaccination. In the course of the quarterly RI LQAS, information on the child immunization card of each of the children sampled was recorded by the interviewer/data collectors, the immunization history and the mothers/caregivers recall of their child immunization was also recorded. When the date of the administered antigen was recorded on the child immunization card, all the information is directly copied by the Interviewer/data collector. Whenever there is any discrepancy between the antigen given and the date the antigen was administered then, the interviewer/data collector collects the antigen that was marked on the immunization card from the mothers/caregivers of the child. Mothers/caregivers were given the opportunity to recall any vaccine given to their child but not recorded on the child's immunization card. For those children who do not have an immunization card whose mothers/caregivers declared their immunization card missing, the history of vaccination provided by the mothers/caregivers was used and recorded for such set of children.

The reason for adopting cross sectional study in this research work is because of the need to estimate the prevalence of the outcome of interest of the population of children 0-11 years of age, most importantly for the purpose of public health planning, (Levin 2006). The RI LQAS is being conducted every quarter in 18 worst performing states (very high priority states) which includes Nasarawa, Niger, Bayelsa and Plateau, Sokoto, Jigawa, Borno, Gombe, Yobe, Zamfara, Kaduna, Kano, Kogi, Taraba, Bauchi, Kebbi, Adamawa, Katsina, (NPHCDA, 2017). Settlements from all the local government areas from these prioritized states are selected each quarter for the RI LQAS. Population Proportionate Sampling (PPS) was used every quarter to determine the specific clusters (settlements) where the assessment will be conducted in each of the LGAs in all the 18 high priority states. For each of the clusters (settlements), the sample size for each of the settlements in all the 18 prioritized states are 10 children who are between the age range of 0-11 months. 


\subsection{ROUTINE IMMUNIZATION LOAD QUALITY ASSURANCE SAMPLING (RI LQAS)}

The Routine Immunization Load Quality Assurance Survey (RI LQAS) is a nationally organized survey pioneered by the National Primary Health Development Agency (NPHCDA) with the support of the World Health Organization (WHO), National Population Commission (NPoPC), National Bureau of Statistics (NBS) etc. LQAS is a quality assurance sampling technique used to assess public health parameters and evaluate program outcomes, it can also be used to provide quick and reasonable estimate of prevalence of diseases, (Rhoda A., et al., 2010). One of the good uses of the LQAS is to monitor and inform decisions on corrective measures based on a particular population. The Routine Immunization Load Quality Assessment (RI LQAS) for measuring RI performance in Nigeria was designed to achieve the following key objectives according to the National Primary Health Care Development Agency (NPHCDA):

1. To estimate the RI performance of all the 23 LGAs in Sokoto State

2. To critically identify the main issues behind nonvaccination of eligible children and also to provide solutions that will improve routine immunization.

3. To provide vital primary sources of vaccination information for mothers/caregivers across the 23 Local Government Areas of Sokoto State.

\subsection{STUDY SETTING}

Sokoto State is one of the nineteen (19) states from northern part of Nigeria. Nigeria as a country has about 36 states and each of the states falls under six geo-political regions namely: North West, North East, North Central, South South, South West, South East. Based on the projected 2006 Nigerian national population census, Sokoto State has a total number of $5,271,037$ population of people, $4 \%$ of this population are under one year of age who are eligible for Routine Immunization services as at 2018 according to the National Population Commission (NPopC) who are mandated by the Nigerian Constitution to conduct national population census. Sokoto State is predominantly a Muslim society dominated by Hausa and Fulani tribes. Sokoto State has about 23 Local Government Areas with 244 wards scattered across the 23 LGAs in the state. Settlements within the 23 Local Government Areas consists of several number of households. The state has a total number of 554 health facilities across the 23 LGAs that cater for the routine immunization need of the people in the state. All RI services at both rural and urban communities across Sokoto State are conducted at the Tertiary, Secondary and Primary Health Care Centers scattered across the 23 local government areas of the state. Routine Immunization services at the health facilities are managed at the state through the Sokoto State Primary Health Care Development Agency (SSPHCDA) who are mandated by the laws of the state to ensure each child between the ages of $0-11$ months is fully immunized. The state Primary Health
Care Development Agency ensures all the health facilities in the state fully conduct RI services by providing the right manpower and ensure the availability of vaccines during both fixed and outreach sessions of the immunization strategy. Each and every community is attached to a particular health facility for RI Services based on location and distance of the community where he or she comes from to the health facility for routine immunization services. For the purpose of this research study all the settlements in the entire state constitute what is called a cluster.

\subsection{STUDY DESIGN}

A cross sectional study was conducted at the community level and the communities were randomly selected across the 23 LGAs of the state. The respondents for this study are mothers/caregivers of the children sampled in the course of this study. For any child to be eligible for the sampling, that child must be between the age range of $0-11$ months old at the time of the RI LQAS survey.

\subsection{SOURCE OF DATA}

This research study made use of the Sokoto State, Routine Immunization Load Quality Assurance (RI LQAS, 2018) data. The RI LQAS 2018 data was obtained from the Sokoto State Primary Health Care Development Agency who are the custodian of the state routine immunization data. The RI LQAS data was the responses of mothers/caregivers of children 0-11 months who were administered the LQAS questionnaire during the conduct of the survey across all the 23 Local Government Areas of the state. The data received from the mothers/caregivers of children 0-11 months was collected from the child immunization card, vaccination history was also used in places where mothers/caregivers of a child cannot produce their child vaccination card due to either misplacement of the vaccination card or vaccination was not recorded on the child's card. During the conduct of the four cycles of the survey in all the 23 LGAs of Sokoto State, a total number of 2,794 Male and 2,726 Female children between the ages of 0-11 months were surveyed.

\subsection{STUDY POPULATION}

The study population for this research study is children aged 0-11 months both male and female born in Sokoto State who are eligible for routine immunization services in all the 23 Local Government Areas in the state and population size is the total number of children 0-11 months that are sampled in the study. The study population composed of 1,380 children per cycle of the LQAS survey and in total 5,520 children both (Male and Female) formed the population of all the children surveyed in four cycles of the RI LQAS conducted in Sokoto State in the year 2018

\subsection{SAMPLE SIZE}


The Routine Immunization Load Quality Assurance sampling (RI LQAS) sample size was a state representative and cover the entire population of children of 0-11 months residing at the communities in 23 Local Government Area (LGAs) of Sokoto State. All the 23 LGAs are selected for the RI LQAS. The settlements (Clusters) where the LQAS survey was conducted in the 23 LGAs was determined using (PPS), Population Proportionate Sampling. The sample for each given cluster (Settlement) is 10 children whose age range falls within 0-11 months. The total sample size for each of the 23 LGAs is 60 eligible children. In each of the four cycles of the RI LQAS conducted in 2018, 60 children aged 0-11 months were sampled from the 23 LGAs which means a total number of 1,380 children where sample in each cycle of the LQAS while 5,520 is the total number of children sampled in four cycles of the LQAS survey conducted in the year 2018.

For the fact that the responses of the LQAS variable is openended and the multiple choice are not properly recorded. This made the variable to be unsafe to be included in the hypothesis testing. Nevertheless, the sample size (60 in each LGA) of the LQAS 2018 surveys is robust enough to address the research objectives up till LGA level.

The sample size is calculated based on this formula:

$$
\begin{aligned}
& \mathrm{N}=1200 \text {, and } \mathrm{n}=60 . \Rightarrow \text { sampling fraction/interval = } \\
& 1200 / 60=20
\end{aligned}
$$

The LQAS survey classified that areas of interest (lots) as either acceptable or unacceptable level of vaccine coverage using the following:

- $\quad$ Sample of individuals (n).

- A decision value (d) or number of unvaccinated individuals in the lot (n).

In calculating the sample interval for the study: The cumulative population of the children 0-11 months of age was divided by the sampling number which is 30 .

The population sample was determined using the LQAS recommended sample size calculation which incorporates the population size, margin of error, and sampling confidence level before arriving at the actual sample size for the study.

Due to the way and manner the settlements (clusters) are sampled, there is high tendency that a settlement may likely be sampled more than once within four cycles of the assessment that is conducted in a year. Only children who fall within the age bracket of 0-11 months are eligible for the survey.

\subsection{DATA ANALYSIS}

Statistical Package for Social Sciences (SPSS) was used for the analysis. Two major types of analyses were conducted on the RI LQAS raw data. They are 'descriptive' and 'inferential' analyses.

Descriptive analysis used frequencies and percentages to summarize the variables in tables. Level of knowledge of the caregivers and the prevalence of routine vaccination among children 0-11 months of age were also measured.
Additionally, descriptive analysis depicted the trend of immunization coverage of the 23 LGAs in Sokoto State over a period of the four Quarters (i.e. Q1, Q2 Q3 and Q4) in 2018.

On the other hand, Chi-square $\left(\chi^{2}\right)$ was the specific inferential statistic used to test the association between the outcome variable (i.e. routine immunization coverage) and two exposure variables (i.e. gender of child and age of child). Chi-square was used because the dependent variable (routine immunization coverage) used is categorical. The pvalue $<=0.05$ was considered for the hypotheses testing of this study.

Below is the description of the variables used for inferential statistical analysis:

\begin{tabular}{|c|c|c|c|c|}
\hline Name/Label & Value Labels & Measure & Type & Description \\
\hline $\begin{array}{l}\text { Immunization } \\
\text { Status }\end{array}$ & $\begin{array}{l}1= \\
\text { Fully/Partially } \\
\text { Immunized } \\
0=\text { Not } \\
\text { Immunized }\end{array}$ & Nominal & Categorical & $\begin{array}{l}\text { Dependent } \\
\text { (Outcome) }\end{array}$ \\
\hline $\begin{array}{l}\text { Gender of } \\
\text { Child }\end{array}$ & $\begin{array}{l}1=\text { Male } \\
2=\text { Female }\end{array}$ & Nominal & Categorical & $\begin{array}{l}\text { Independent } \\
\text { (Exposure) }\end{array}$ \\
\hline Age of Child & $\begin{array}{l}1=24 \mathrm{hrs} \\
2=0-2 \mathrm{wk} \\
3=3-5 \mathrm{wk} \\
4=6-9 \mathrm{wk} \\
5=10-13 \mathrm{wk} \\
6=14-15 \mathrm{wk} \\
7=4-8 \mathrm{~m} \\
8=9-11 \mathrm{~m}\end{array}$ & Nominal & Categorical & $\begin{array}{l}\text { Independent } \\
\text { (Exposure) }\end{array}$ \\
\hline
\end{tabular}

Table 1: Independent Variables

Source: LQAS 2018, Sokoto State

It is essential to note that data analysis of this research work was restricted to available variables in the LQAS 2018 survey datasets. Also, some of the variables were not properly coded. Hence, it took time to recode and arrange them properly for the purpose of this study, because, the LQAS questionnaire was not structured to collect Socio demographic characteristics of the caregivers/mothers, that is why this research study cannot run other statistics apart from ChiSquare. There is no appropriate variable to be used for inferential analysis apart from 'Immunization Coverage, 'age' and 'gender' of children.

\subsection{ETHICAL CLEARANCE}

This research study is a secondary data analysis. The datasets for the routine immunization Load Quality survey (RI LQAS) is available to the general public obtainable at the Sokoto State Primary Health Care Development Agency who are the custodian of the state routine immunization data. For the sake of research ethics, approval for the use of the LQAS 2018 data was granted by the Sokoto State Primary Health Care (SSPHCDA) for this research work. The research proposal was submitted to the SSPHCDA where purpose and objectives 
of conducting this research in Sokoto State was described before the approval was granted. The LQAS dataset was provided in an Excel Sheet format by the Sokoto State
Primary Health Care Development Agency (SSPHCDA) after granting the approval for the use of the LQAS data. 


\subsection{FINDINGS, ANALYSIS AND EVLUATION}

This chapter covers descriptive and inferential analyses of the determinants of childhood routine immunization coverage in Sokoto State, North West Nigeria. On the descriptive analysis aspect, frequencies and percentages of the variables were summarized in tables. These include demographics of the children surveyed, immunization coverage and the determinants. On the other hand, chi-square was (the specific inferential statistic) used to test the association between the outcome variable (i.e. routine immunization coverage) and the exposure variables (i.e. gender of child and age of child).

It is important to note that data are extracted from Routine Immunization Lot Quality Assurance Sampling 2018 Survey (RI LQAS 2018) datasets. Thus, variables of the RI LQAS 2018 datasets (which address this study's objectives and questions) were relied on for data analysis.

\subsection{DEMOGRAPHIC CHARACTERISTICS OF CHILDREN}

Tables 2, 3 and 4 below show the demographics of children whose information was collected during the LQAS 2018 surveys. 'Quarters' simply refer to Q1, Q2, Q3 and Q4 which in turn mean the period of January to March, April to June, July to September and October to December respectively in 2018. The total number of children whose information was collected in each quarter is 1,380 .

Table 2: Gender Distribution of Children

\begin{tabular}{|l|c|c|c|c|c|c|c|c|}
\hline & \multicolumn{2}{|c|}{ Q1 } & \multicolumn{2}{c|}{ Q2 } & \multicolumn{2}{c|}{ Q3 } & \multicolumn{2}{c|}{ Q4 } \\
\cline { 2 - 9 } & Frequency & \% & Frequency & \% & Frequency & \% & Frequency & \% \\
\hline Male & 693 & 50.2 & 696 & 50.4 & 703 & 50.9 & 702 & 50.9 \\
\hline Female & 687 & 49.8 & 684 & 49.6 & 677 & 49.1 & 678 & 49.1 \\
\hline Total & $\mathbf{1 , 3 8 0}$ & $\mathbf{1 0 0 . 0}$ & $\mathbf{1 , 3 8 0}$ & $\mathbf{1 0 0 . 0}$ & $\mathbf{1 , 3 8 0}$ & $\mathbf{1 0 0 . 0}$ & $\mathbf{1 , 3 8 0}$ & $\mathbf{1 0 0 . 0}$ \\
\hline
\end{tabular}

\section{Source: LQAS 2018, Sokoto State}

The table above shows that the gender of children surveyed, across the Quarters, is equally distributed in the four quarters. The majority of immunized children is male and the number follows the same trend throughout all the Quarters.

Table 3: Age Distribution of Children

\begin{tabular}{|c|c|c|c|c|c|c|c|c|}
\hline & \multicolumn{2}{|c|}{ Q1 } & \multicolumn{2}{c|}{ Q2 } & \multicolumn{2}{c|}{ Q3 } & \multicolumn{2}{c|}{ Q4 } \\
\cline { 2 - 10 } & Frequency & \% & Frequency & \% & Frequency & \% & Frequency & \% \\
\hline $24 \mathrm{hrs}$ & 11 & 0.8 & 8 & 0.6 & 8 & 0.6 & 10 & 0.7 \\
\hline $0-2 \mathrm{wk}$ & 61 & 4.4 & 66 & 4.8 & 64 & 4.6 & 72 & 5.2 \\
\hline $3-5 \mathrm{wk}$ & 144 & 10.4 & 128 & 9.3 & 101 & 7.3 & 140 & 10.1 \\
\hline $6-9 \mathrm{wk}$ & 139 & 10.1 & 139 & 10.1 & 118 & 8.6 & 149 & 10.8 \\
\hline $10-13 \mathrm{wk}$ & 89 & 6.4 & 105 & 7.6 & 95 & 6.9 & 118 & 8.6 \\
\hline $14-15 \mathrm{wk}$ & 109 & 7.9 & 86 & 6.2 & 84 & 6.1 & 96 & 7.0 \\
\hline $4-8 \mathrm{~m}$ & 456 & 33.0 & 509 & 36.9 & 518 & 37.5 & 406 & 29.4 \\
\hline 9-11m & 371 & 26.9 & 339 & 24.6 & 392 & 28.4 & 389 & 28.2 \\
\hline Total & $\mathbf{1 , 3 8 0}$ & $\mathbf{1 0 0 . 0}$ & $\mathbf{1 , 3 8 0}$ & $\mathbf{1 0 0 . 0}$ & $\mathbf{1 , 3 8 0}$ & $\mathbf{1 0 0 . 0}$ & $\mathbf{1 , 3 8 0}$ & $\mathbf{1 0 0 . 0}$ \\
\hline
\end{tabular}

Source: LQAS 2018, Sokoto State

In table above, it is obvious that about one-third of children are between age 4-8 month. This is closely followed by those in age 9-11 months. A total number of 1,380 children were surveyed in each of the quarters of the survey which makes the total number of children surveyed for quarter (Q1, Q2, Q3 and Q4) of the survey conducted from January - December 2018 to be 5,520 children. 
$\underline{\text { Routine Immunization Coverage in Sokoto State }}$

Table 4: Immunization Status of Children

\begin{tabular}{|l|c|c|c|c|c|c|c|c|}
\hline & \multicolumn{2}{|c|}{ Q1 } & \multicolumn{2}{c|}{ Q2 } & \multicolumn{2}{c|}{ Q3 } & \multicolumn{2}{c|}{ Q4 } \\
\cline { 2 - 9 } & Frequency & \% & Frequency & \% & Frequency & \% & Frequency & \% \\
\hline $\begin{array}{l}\text { Fully } \\
\text { Immunized* }\end{array}$ & 588 & 42.6 & 587 & 42.5 & 519 & 37.6 & 703 & 50.9 \\
\hline $\begin{array}{l}\text { Partially } \\
\text { Immunized }\end{array}$ & 512 & 37.1 & 545 & 39.5 & 477 & 34.6 & 436 & 31.6 \\
\hline $\begin{array}{l}\text { Not } \\
\text { Immunized }\end{array}$ & 280 & 20.3 & 248 & 18.0 & 384 & 27.8 & 241 & 17.5 \\
\hline Total & $\mathbf{1 , 3 8 0}$ & $\mathbf{1 0 0 . 0}$ & $\mathbf{1 , 3 8 0}$ & $\mathbf{1 0 0 . 0}$ & $\mathbf{1 , 3 8 0}$ & $\mathbf{1 0 0 . 0}$ & $\mathbf{1 , 3 8 0}$ & $\mathbf{1 0 0 . 0}$ \\
\hline
\end{tabular}

Source: LQAS 2018, Sokoto State

*Note: Fully immunized in this context refer to immunization status of the child for his/her age.

Table 5ai: Immunization Status of Children by Age in Quarter 1

\begin{tabular}{|c|c|c|c|c|c|c|c|c|c|c|c|c|c|c|c|c|c|}
\hline & & \multicolumn{2}{|c|}{$24 \mathrm{hrs}$} & \multicolumn{2}{|c|}{$0-2$ wk } & \multicolumn{2}{|c|}{$3-5 w k$} & \multicolumn{2}{|c|}{$6-9 \mathrm{wk}$} & \multicolumn{2}{|c|}{$10-13$ wk } & \multicolumn{2}{|c|}{$14-15 \mathrm{wk}$} & \multicolumn{2}{|c|}{$4-8 m$} & \multicolumn{2}{|c|}{$9-11 \mathrm{~m}$} \\
\hline \multirow{5}{*}{ Q1 } & & $\mathrm{N}$ & $\%$ & $\mathrm{~N}$ & $\%$ & $\mathrm{~N}$ & $\%$ & $\mathrm{~N}$ & $\%$ & $\mathrm{~N}$ & $\%$ & $\mathrm{~N}$ & $\%$ & $\mathrm{~N}$ & $\%$ & $\mathrm{~N}$ & $\%$ \\
\hline & $\begin{array}{l}\text { Fully } \\
\text { Immunized }\end{array}$ & 2 & 18.2 & 36 & 59.0 & 88 & 61.1 & 77 & 55.4 & 50 & 56.2 & 41 & 37.6 & 164 & 36.0 & 130 & 35.0 \\
\hline & $\begin{array}{l}\text { Partially } \\
\text { Immunized }\end{array}$ & 0 & 0.0 & 2 & 3.3 & 22 & 15.3 & 31 & 22.3 & 28 & 31.5 & 50 & 45.9 & 214 & 46.9 & 165 & 44.5 \\
\hline & Not Immunized & 9 & 81.8 & 23 & 37.7 & 34 & 23.6 & 31 & 22.3 & 11 & 12.4 & 18 & 16.5 & 78 & 17.1 & 76 & 20.5 \\
\hline & Total & 11 & 100.0 & 61 & 100.0 & 144 & 100.0 & 139 & 100.0 & 89 & 100.0 & 109 & 100.0 & 456 & 100.0 & 371 & 100.0 \\
\hline
\end{tabular}

Table 5aii: Immunization Status of Children by Age in Quarter 2

\begin{tabular}{|c|c|c|c|c|c|c|c|c|c|c|c|c|c|c|c|c|c|}
\hline & & \multicolumn{2}{|c|}{$24 \mathrm{hrs}$} & \multicolumn{2}{|c|}{$0-2$ wk } & \multicolumn{2}{|c|}{$3-5 \mathrm{wk}$} & \multicolumn{2}{|c|}{$6-9 \mathrm{wk}$} & \multicolumn{2}{|c|}{$10-13 \mathrm{wk}$} & \multicolumn{2}{|c|}{$14-15 \mathrm{wk}$} & \multicolumn{2}{|c|}{$4-8 m$} & \multicolumn{2}{|c|}{$9-11 \mathrm{~m}$} \\
\hline \multirow{5}{*}{ Q2 } & & $\mathrm{N}$ & $\%$ & $\mathrm{~N}$ & $\%$ & $\mathrm{~N}$ & $\%$ & $\mathrm{~N}$ & $\%$ & $\mathrm{~N}$ & $\%$ & $\mathrm{~N}$ & $\%$ & $\mathrm{~N}$ & $\%$ & $\mathrm{~N}$ & $\%$ \\
\hline & $\begin{array}{l}\text { Fully } \\
\text { Immunized }\end{array}$ & 2 & 25.0 & 41 & 62.1 & 84 & 65.6 & 62 & 44.6 & 52 & 49.5 & 16 & 18.6 & 178 & 35.0 & 152 & 44.8 \\
\hline & $\begin{array}{l}\text { Partially } \\
\text { Immunized }\end{array}$ & 0 & 0.0 & 1 & 1.5 & 5 & 3.9 & 48 & 34.5 & 38 & 36.2 & 54 & 62.8 & 245 & 48.1 & 154 & 45.4 \\
\hline & Not Immunized & 6 & 75.0 & 24 & 36.4 & 39 & 30.5 & 29 & 20.9 & 15 & 14.3 & 16 & 18.6 & 86 & 16.9 & 33 & 9.7 \\
\hline & Total & 8 & 100.0 & 66 & 100.0 & 128 & 100.0 & 139 & 100.0 & 105 & 100.0 & 86 & 100.0 & 509 & 100.0 & 339 & 100.0 \\
\hline
\end{tabular}


Table 5aiii: Immunization Status of Children by Age in Quarter 3

\begin{tabular}{|c|c|c|c|c|c|c|c|c|c|c|c|c|c|c|c|c|c|}
\hline & & \multicolumn{2}{|c|}{$24 \mathrm{hrs}$} & \multicolumn{2}{|c|}{$0-2$ wk } & \multicolumn{2}{|c|}{$3-5 \mathrm{wk}$} & \multicolumn{2}{|c|}{ 6-9 wk } & \multicolumn{2}{|c|}{$10-13$ wk } & \multicolumn{2}{|c|}{$14-15 \mathrm{wk}$} & \multicolumn{2}{|c|}{$4-8 \mathrm{~m}$} & \multicolumn{2}{|c|}{$9-11 \mathrm{~m}$} \\
\hline \multirow{5}{*}{ Q3 } & & $\mathrm{N}$ & $\%$ & $\mathrm{~N}$ & $\%$ & $\mathrm{~N}$ & $\%$ & $\mathrm{~N}$ & $\%$ & $\mathrm{~N}$ & $\%$ & $\mathrm{~N}$ & $\%$ & $\mathrm{~N}$ & $\%$ & $\mathrm{~N}$ & $\%$ \\
\hline & $\begin{array}{l}\text { Fully } \\
\text { Immunized }\end{array}$ & 3 & 37.5 & 34 & 53.1 & 60 & 59.4 & 48 & 40.7 & 42 & 44.2 & 27 & 32.1 & 168 & 32.4 & 137 & 34.9 \\
\hline & $\begin{array}{l}\text { Partially } \\
\text { Immunized }\end{array}$ & 0 & 0.0 & 1 & 1.6 & 6 & 5.9 & 30 & 25.4 & 25 & 26.3 & 32 & 38.1 & 207 & 40.0 & 176 & 44.9 \\
\hline & $\begin{array}{l}\text { Not } \\
\text { Immunized }\end{array}$ & 5 & 62.5 & 29 & 45.3 & 35 & 34.7 & 40 & 33.9 & 28 & 29.5 & 25 & 29.8 & 143 & 27.6 & 79 & 20.2 \\
\hline & Total & 8 & 100.0 & 64 & 100.0 & 101 & 100.0 & 118 & 100.0 & 95 & 100.0 & 84 & 100.0 & 518 & 100.0 & 392 & 100.0 \\
\hline
\end{tabular}

Table 5aiv: Immunization Status of Children by Age in Quarter 4

\begin{tabular}{|c|c|c|c|c|c|c|c|c|c|c|c|c|c|c|c|c|c|}
\hline & & \multicolumn{2}{|c|}{$24 \mathrm{hrs}$} & \multicolumn{2}{|c|}{$0-2$ wk } & \multicolumn{2}{|c|}{$3-5 \mathrm{wk}$} & \multicolumn{2}{|c|}{$6-9 \mathrm{wk}$} & \multicolumn{2}{|c|}{$10-13 \mathrm{wk}$} & \multicolumn{2}{|c|}{$14-15 \mathrm{wk}$} & \multicolumn{2}{|c|}{$4-8 m$} & \multicolumn{2}{|c|}{$9-11 \mathrm{~m}$} \\
\hline \multirow{5}{*}{ Q4 } & & $\mathrm{N}$ & $\%$ & $\mathrm{~N}$ & $\%$ & $\mathrm{~N}$ & $\%$ & $\mathrm{~N}$ & $\%$ & $\mathrm{~N}$ & $\%$ & $\mathrm{~N}$ & $\%$ & $\mathrm{~N}$ & $\%$ & $\mathrm{~N}$ & $\%$ \\
\hline & $\begin{array}{l}\text { Fully } \\
\text { Immunized }\end{array}$ & 5 & 50.0 & 52 & 72.2 & 97 & 69.3 & 94 & 63.1 & 57 & 48.3 & 37 & 38.5 & 189 & 46.6 & 172 & 44.2 \\
\hline & $\begin{array}{l}\text { Partially } \\
\text { Immunized }\end{array}$ & 0 & 0.0 & 2 & 2.8 & 8 & 5.7 & 23 & 15.4 & 39 & 33.1 & 41 & 42.7 & 153 & 37.7 & 170 & 43.7 \\
\hline & $\begin{array}{l}\text { Not } \\
\text { Immunized }\end{array}$ & 5 & 50.0 & 18 & 25.0 & 35 & 25.0 & 32 & 21.5 & 22 & 18.6 & 18 & 18.8 & 64 & 15.8 & 47 & 12.1 \\
\hline & Total & 10 & 100.0 & 72 & 100.0 & 140 & 100.0 & 149 & 100.0 & 118 & 100.0 & 96 & 100.0 & 406 & 100.0 & 389 & 100.0 \\
\hline
\end{tabular}

As shown tables 5ai to 5aiv above, about half of children between 0 and 13 weeks are fully immunized. The percentages continue to drop as their ages decrease.

Table 6: Immunization Status of Children by Gender

\begin{tabular}{|c|c|c|c|c|c|c|c|c|c|c|c|c|c|c|c|c|}
\hline & \multicolumn{4}{|c|}{ Q1 } & \multicolumn{4}{|c|}{ Q2 } & \multicolumn{4}{|c|}{ Q3 } & \multicolumn{4}{|c|}{ Q4 } \\
\hline & \multicolumn{2}{|c|}{ Male } & \multicolumn{2}{|c|}{ Female } & \multicolumn{2}{|c|}{ Male } & \multicolumn{2}{|c|}{ Female } & \multicolumn{2}{|c|}{ Male } & \multicolumn{2}{|c|}{ Female } & \multicolumn{2}{|c|}{ Male } & \multicolumn{2}{|c|}{ Female } \\
\hline & $\mathbf{N}$ & $\%$ & $\mathbf{N}$ & $\%$ & $\mathbf{N}$ & $\%$ & $\mathbf{N}$ & $\%$ & $\mathbf{N}$ & $\%$ & $\mathbf{N}$ & $\%$ & $\mathbf{N}$ & $\%$ & $\mathbf{N}$ & $\%$ \\
\hline $\begin{array}{l}\text { Fully } \\
\text { Immunized }\end{array}$ & 296 & 42.7 & 292 & 42.5 & 303 & 43.5 & 284 & 41.5 & 266 & 37.8 & 253 & 37.4 & 375 & 53.4 & 328 & 48.4 \\
\hline $\begin{array}{l}\text { Partially } \\
\text { Immunized }\end{array}$ & 260 & 37.5 & 252 & 36.7 & 257 & 36.9 & 288 & 42.1 & 239 & 34.0 & 238 & 35.2 & 218 & 31.1 & 218 & 32.2 \\
\hline $\begin{array}{l}\text { Not } \\
\text { Immunized }\end{array}$ & 137 & 19.8 & 143 & 20.8 & 136 & 19.5 & 112 & 16.4 & 198 & 28.2 & 186 & 27.5 & 109 & 15.5 & 132 & 19.5 \\
\hline Total & 693 & 100.0 & 687 & 100.0 & 696 & 100.0 & 684 & 100.0 & 703 & 100.0 & 677 & 100.0 & 702 & 100.0 & 678 & 100.0 \\
\hline
\end{tabular}

Source: LQAS 2018, Sokoto State

In Q1, more male (42.7\%) are fully immunized compare to the female (42.5\%), while more female (20.8\%) are not immunized compare to male (19.8\%). In Q2, more male (43.5\%) are fully immunized compare to the female (41.5\%), and more male (19.5\%) are not immunized compare to female (16.4\%). Immunization coverage in Q3 is similar to that of Q2 as it is observed that more male (37.8\%) are fully immunized compare to the female (37.4\%), and more male $(28.2 \%)$ are not immunized compare to female $(27.5 \%)$. Q4 has the highest percentage of fully immunized children as shown in the table - more male (53.4\%) are fully immunized compare to the female (48.4\%), while more female $(19.5 \%)$ are not immunized compare to male $(15.5 \%)$. Overall, more male children are fully immunized.

With regards to the immunization status of children (0-11month), it is clearly observed from the data that about $20 \%$ of children in Sokoto State have never received any vaccine. Furthermore, it can be seen that above $40 \%$ are fully immunized up till their respective age. However, this does not mean that they have completed reception of the vaccine. Some of these children (who are categorized as fully immunized) may not complete their vaccine when they are 12 months old. In summary, we can assume that if the cohort (who are categorized as fully immunized) is monitored till they all reach 12 months, the proportion of 'fully immunized' will continue to reduce, while the proportion of those 'partially immunized' will continue to increase. 
Table 7: Distribution of children not immunized by Local Government Areas

\begin{tabular}{|c|c|c|c|c|c|c|c|c|}
\hline & \multicolumn{2}{|c|}{ Q1 } & \multicolumn{2}{|c|}{ Q2 } & \multicolumn{2}{|c|}{ Q3 } & \multicolumn{2}{|c|}{ Q4 } \\
\hline & Frequency & $\%$ & Frequency & $\%$ & Frequency & $\%$ & Frequency & $\%$ \\
\hline Binji & 2 & 0.7 & 2 & 0.8 & 10 & 2.6 & 5 & 2.1 \\
\hline Bodinga & 9 & 3.2 & 10 & 4.0 & 37 & 9.6 & 10 & 4.1 \\
\hline Dange-Shuni & 32 & 11.4 & 34 & 13.7 & 15 & 3.9 & 8 & 3.3 \\
\hline Gada & 21 & 7.5 & 11 & 4.4 & 17 & 4.4 & 8 & 3.3 \\
\hline Goronyo & 10 & 3.6 & 15 & 6.0 & 6 & 1.6 & 13 & 5.4 \\
\hline Gudu & 10 & 3.6 & 1 & 0.4 & 8 & 2.1 & 8 & 3.3 \\
\hline Gwadabawa & 15 & 5.4 & 14 & 5.6 & 40 & 10.4 & 7 & 2.9 \\
\hline Illela & 4 & 1.4 & 6 & 2.4 & 2 & 0.5 & 8 & 3.3 \\
\hline Isa & 9 & 3.2 & 15 & 6.0 & 3 & 0.8 & 7 & 2.9 \\
\hline Kebbe & 0 & 0.0 & 16 & 6.5 & 4 & 1.0 & 5 & 2.1 \\
\hline Kware & 19 & 6.8 & 6 & 2.4 & 31 & 8.1 & 0 & 0.0 \\
\hline Rabah & 10 & 3.6 & 3 & 1.2 & 24 & 6.3 & 14 & 5.8 \\
\hline Sabon Birni & 21 & 7.5 & 2 & 0.8 & 31 & 8.1 & 13 & 5.4 \\
\hline Shagari & 18 & 6.4 & 8 & 3.2 & 18 & 4.7 & 30 & 12.4 \\
\hline Silame & 1 & 0.4 & 7 & 2.8 & 9 & 2.3 & 19 & 7.9 \\
\hline Sokoto North & 2 & 0.7 & 4 & 1.6 & 8 & 2.1 & 4 & 1.7 \\
\hline Sokoto South & 14 & 5.0 & 18 & 7.3 & 7 & 1.8 & 8 & 3.3 \\
\hline Tambuwal & 19 & 6.8 & 7 & 2.8 & 11 & 2.9 & 14 & 5.8 \\
\hline Tangaza & 2 & 0.7 & 14 & 5.6 & 22 & 5.7 & 5 & 2.1 \\
\hline Tureta & 20 & 7.1 & 23 & 9.3 & 30 & 7.8 & 24 & 10.0 \\
\hline Wamakko & 14 & 5.0 & 14 & 5.6 & 33 & 8.6 & 20 & 8.3 \\
\hline Wurno & 19 & 6.8 & 13 & 5.2 & 17 & 4.4 & 6 & 2.5 \\
\hline Yabo & 9 & 3.2 & 5 & 2.0 & 1 & 0.3 & 5 & 2.1 \\
\hline Total & 280 & 100.0 & 248 & 100.0 & 384 & 100.0 & 241 & 100.0 \\
\hline
\end{tabular}

Source: LQAS 2018, Sokoto State

As shown in table 7, above, Dange-Shuni LGA had the highest proportion of children who have never be immunized in Quarters 1 and 2. While Gwadabawa and Shagari LGAs had the highest proportion of children who have not been immunized in Quarter 3 and 4 respectively. On the other hand, Kebbe, Gudu, Yabo and Kware LGAs had the least number of children who have never been immunized in Quarters 1, 2, 3 and 4 respectively. Reasons for differences in the coverage of immunization from Q1 to Q4 may be due, partly, to decrease/increase in the efforts of stakeholders on one hand, and intervention Programmes of NonGovernmental Organizations (NGOs) in selected LGAs on the other hand.

Table 8: Distribution of children with Immunization Card

\begin{tabular}{|l|c|c|c|c|c|c|c|c|}
\hline & \multicolumn{2}{|c|}{ Q1 } & \multicolumn{2}{c|}{ Q2 } & \multicolumn{2}{c|}{ Q3 } & \multicolumn{2}{c|}{ Q4 } \\
\cline { 2 - 10 } & Frequency & \% & Frequency & \% & Frequency & \% & Frequency & \% \\
\hline Have Card & 1,073 & 77.8 & 1,118 & 81.0 & 959 & 69.5 & 1,039 & 75.3 \\
\hline $\begin{array}{l}\text { Have } \\
\text { No Card }\end{array}$ & 307 & 22.2 & 262 & 19.0 & 421 & 30.5 & 341 & 24.7 \\
\hline Total & $\mathbf{1 , 3 8 0}$ & $\mathbf{1 0 0 . 0}$ & $\mathbf{1 , 3 8 0}$ & $\mathbf{1 0 0 . 0}$ & $\mathbf{1 , 3 8 0}$ & $\mathbf{1 0 0 . 0}$ & $\mathbf{1 , 3 8 0}$ & $\mathbf{1 0 0 . 0}$ \\
\hline
\end{tabular}

\section{Source: LQAS 2018, Sokoto State}

This table shows that about 20\% of children (in each of the Quarters) do not have immunization card. The highest proportion of children with no immunization card was witnessed in quarter 3 i.e. $30.5 \%$

Table 9: Distribution of children with no immunization card by Gender

\begin{tabular}{|l|c|c|c|c|c|c|c|c|}
\hline & \multicolumn{2}{|c|}{ Q1 } & \multicolumn{2}{c|}{ Q2 } & \multicolumn{2}{c|}{ Q3 } & \multicolumn{2}{c|}{ Q4 } \\
\cline { 2 - 10 } & Frequency & \% & Frequency & \% & Frequency & \% & Frequency & \% \\
\hline Male & 149 & 48.5 & 141 & 53.8 & 212 & 50.4 & 155 & 45.5 \\
\hline Female & 158 & 51.5 & 121 & 46.2 & 209 & 49.6 & 186 & 54.5 \\
\hline Total & $\mathbf{3 0 7}$ & $\mathbf{1 0 0 . 0}$ & $\mathbf{2 6 2}$ & $\mathbf{1 0 0 . 0}$ & $\mathbf{4 2 1}$ & $\mathbf{1 0 0 . 0}$ & $\mathbf{3 4 1}$ & $\mathbf{1 0 0 . 0}$ \\
\hline
\end{tabular}

Source: LQAS 2018, Sokoto State

According to this table, there is no notable difference in the gender split of children who do not have immunization card. 
Table 10: Distribution of children with no immunization card by Local Government Areas

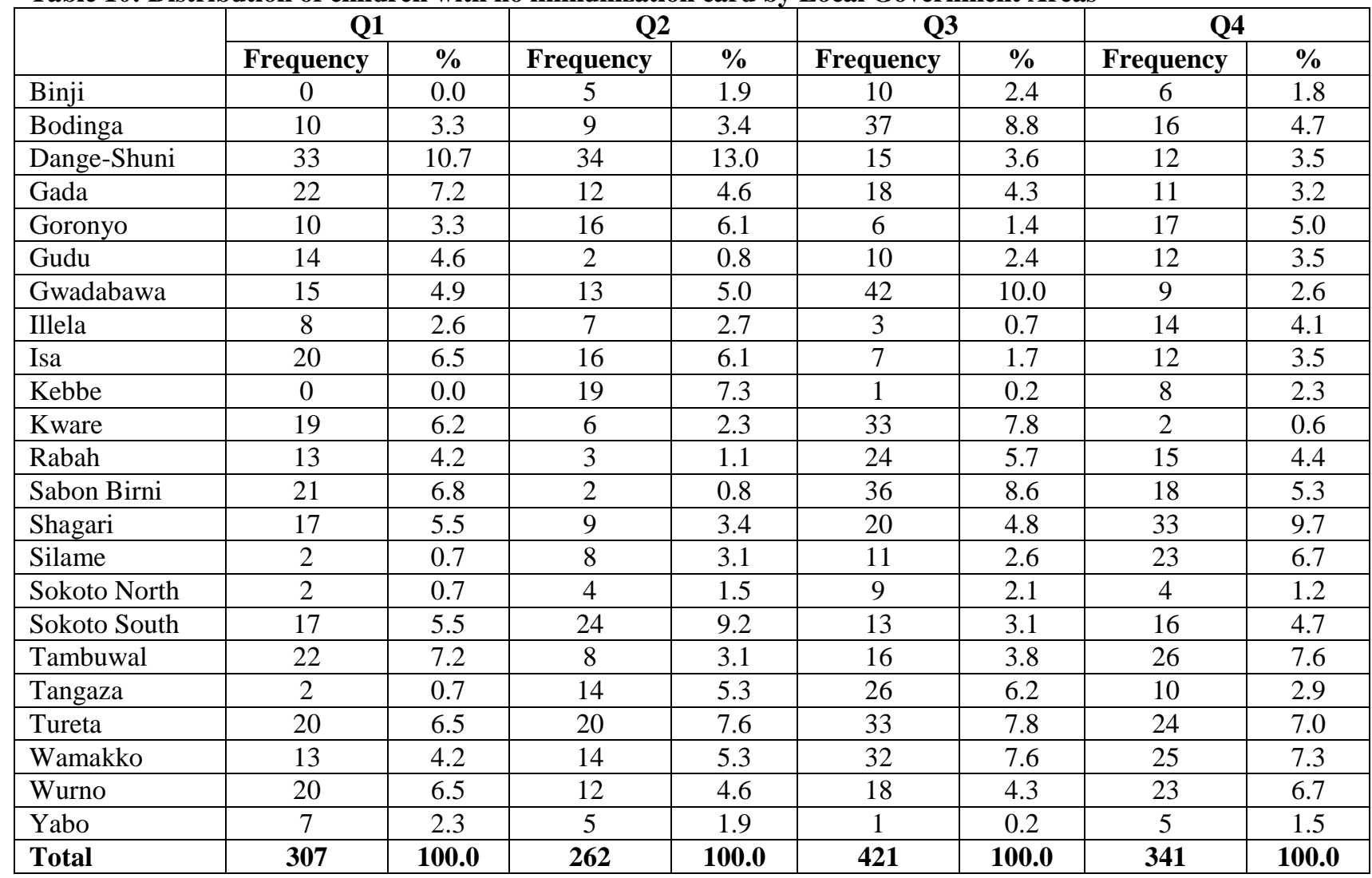

Source: LQAS 2018, Sokoto State

As shown in this table, Dange-Shuni LGA had the highest number of children with no immunization card in Quarters 1 and 2. In quarters 3 and 4, Gwadabawa and Shagari LGAs had the highest number of children with no immunization card respectively. Immunization card is very important because it is one of the ways for caregivers and service providers to monitor children's immunization status. It also gives full information about which vaccine has been received and also status of the child immunization whether fully immunized or not.

\section{Determinants of Vaccination in Sokoto State}

There are many factors responsible for low coverage of routine immunization in Sokoto State. Some of these factors were mentioned by caregivers/mothers during the LQAS 2018 quarterly surveys. During the survey, the factors determining Routine Immunization coverage were captured with questions on: 1) Reasons for not Fully Immunized, 2) Reasons for no immunization card and 3) Sources of information about routine immunization. The results are shown in the following tables:

Table 11: Reasons for not Fully Immunized (i.e. Partially/Not Immunized)

\begin{tabular}{|c|l|c|c|c|c|}
\hline S/No & \multicolumn{1}{|c|}{$\begin{array}{c}\text { Ten Most Mentioned Reasons for not Fully } \\
\text { Immunized }\end{array}$} & $\begin{array}{c}\text { Q1 } \\
(\mathbf{n = 7 9 2}) *\end{array}$ & $\begin{array}{c}\text { Q2 } \\
(\mathbf{n = 7 9 3}) *\end{array}$ & $\begin{array}{c}\text { Q3 } \\
(\mathbf{n = 8 6 1}) *\end{array}$ & $\begin{array}{c}\text { Q4 } \\
(\mathbf{n}=\mathbf{6 7 7})^{*}\end{array}$ \\
\hline 1 & Unable take child to health facility & $16.9 \%$ & $31.9 \%$ & $32.6 \%$ & $26.4 \%$ \\
\hline 2 & Unaware of EPI Schedule & $8.0 \%$ & $5.0 \%$ & $9.9 \%$ & $15.8 \%$ \\
\hline 3 & Unaware of Immunization need & $9.5 \%$ & $5.0 \%$ & $9.9 \%$ & $10.8 \%$ \\
\hline 4 & Vaccinator absent & $6.7 \%$ & $9.5 \%$ & $7.4 \%$ & $4.3 \%$ \\
\hline 5 & Caregiver forgot & $6.6 \%$ & $11.3 \%$ & $11.3 \%$ & $8.4 \%$ \\
\hline 6 & No need felt & $2.3 \%$ & $6.6 \%$ & $8.2 \%$ & $9.0 \%$ \\
\hline 7 & Adverse Effect Following Immunization (AEFI) & $2.3 \%$ & $8.8 \%$ & $5.3 \%$ & $4.1 \%$ \\
\hline 8 & Place and time unknown & $1.4 \%$ & $2.6 \%$ & $0.7 \%$ & $1.8 \%$ \\
\hline 9 & No faith/belief in immunization & $7.3 \%$ & $3.4 \%$ & $3.1 \%$ & $7.1 \%$ \\
\hline 10 & No Vaccine at the health facility & $2.9 \%$ & $1.1 \%$ & $2.2 \%$ & $1.8 \%$ \\
\hline
\end{tabular}

Source: LQAS 2018, Sokoto State

*Note: This is a combination of 'partially immunized' and 'no immunized'. Also, this is a multiple response question - the total may not be equal to $100 \%$ 
The table shown below contains most mentioned reasons why children are not fully immunized. It is clearly shown that knowledge and perception of caregivers contribute - this encompasses inability of caregivers to take their children to the health facility for vaccination and unawareness of immunization schedule and need. Additionally, absence of vaccinator/service provider/Health worker is one of the reasons why children are not fully immunized. Some caregivers also mentioned that Adverse Effect Following Immunization (AEFI) is one reason why their children and not fully immunized.

Table 12: Reasons for no immunization card

\begin{tabular}{|c|l|c|c|c|c|}
\hline S/No & \multicolumn{1}{|c|}{$\begin{array}{c}\text { Three Most Mentioned Reasons for no } \\
\text { immunization card }\end{array}$} & $\begin{array}{c}\mathbf{Q 1} \\
(\mathbf{n}=\mathbf{3 0 7}) *\end{array}$ & $\begin{array}{c}\mathbf{Q 2} \\
(\mathbf{n}=\mathbf{2 6 2}) *\end{array}$ & $\begin{array}{c}\text { Q3 } \\
(\mathbf{n}=\mathbf{4 2 1})^{*}\end{array}$ & $\begin{array}{c}\text { Q4 } \\
(\mathbf{n}=\mathbf{3 4 1}) *\end{array}$ \\
\hline 1 & Never gone for Routine Immunization & $73.6 \%$ & $74.4 \%$ & $80.0 \%$ & $61.6 \%$ \\
\hline 2 & Not issued & $16.3 \%$ & $16.8 \%$ & $11.4 \%$ & $25.5 \%$ \\
\hline 3 & Lost/destroyed/misplaced & $7.2 \%$ & $6.9 \%$ & $8.6 \%$ & $12.6 \%$ \\
\hline
\end{tabular}

The table above shows that there are three main reasons for no immunization card. They are: Caregivers never gone to health facility, card not issued by service provider and lost and card being destroyed or misplaced. It is obvious that more than $60 \%$ of Caregivers/Mothers with no immunization card have never gone to any health facility for routine immunization.

Table 13: Main Source of Information about Routine Immunization

\begin{tabular}{|c|l|c|c|c|c|}
\hline S/No. & Ten Most Mentioned Source of Information & $\begin{array}{c}\mathbf{Q 1} \\
(\mathbf{n = 1 , 3 8 0})\end{array}$ & $\begin{array}{c}\text { Q2 } \\
(\mathbf{n = 1 , 3 8 0})\end{array}$ & $\begin{array}{c}\text { Q3 } \\
(\mathbf{n = 1 , 3 8 0})\end{array}$ & $\begin{array}{c}\text { Q4 } \\
(\mathbf{n = 1 , 3 8 0})\end{array}$ \\
\hline 1 & Health Worker & $58.4 \%$ & $63.8 \%$ & $60.7 \%$ & $68.6 \%$ \\
\hline 2 & Town announcer & $44.3 \%$ & $47.2 \%$ & $46.4 \%$ & $51.3 \%$ \\
\hline 3 & Polio vaccinator & $29.8 \%$ & $35.9 \%$ & $30.8 \%$ & $40.6 \%$ \\
\hline 4 & Community leader & $26.4 \%$ & $23.7 \%$ & $39.2 \%$ & $30.1 \%$ \\
\hline 5 & Voluntary Community Mobilizer (VCM) & $26.0 \%$ & $35.8 \%$ & $13.0 \%$ & $20.3 \%$ \\
\hline 6 & Radio & $15.1 \%$ & $6.9 \%$ & $15.8 \%$ & $20.9 \%$ \\
\hline 7 & Family members & $5.1 \%$ & $2.5 \%$ & $4.1 \%$ & $12.8 \%$ \\
\hline 8 & Mosques/Church & $3.2 \%$ & $1.6 \%$ & $1.0 \%$ & $2.4 \%$ \\
\hline 9 & Neighbors & $1.3 \%$ & $4.0 \%$ & $4.7 \%$ & $4.8 \%$ \\
\hline 10 & Women group & $0.6 \%$ & $2.8 \%$ & $2.2 \%$ & $0.6 \%$ \\
\hline
\end{tabular}

The table above contains ten most mentioned sources of information on routine immunization. They are: health workers, Town announcer, polio Vaccinator, Community leaders, community mobilizer VCM, Radio, Family members, religion centers, neighbors and women group. It is clear from the table that more than half of Caregivers/Mothers get information on routine immunization from health workers. Also, the effort town announcers cannot be underestimated as it is shown that about half of the Caregivers/Mothers get information from town announcers.

\section{Hypotheses Testing}

This section deals with the analysis/interpretation of the study hypotheses. The statistic adopted is Chi-square $(\chi 2)$. This is because the outcome variable is categorical. The exposure variables are 'gender' and 'age', while the outcome variable is 'immunization status of child'. The level of significant used in the analysis is $5 \%$ (i.e. 0.05 ).

The decision rule is that any $\mathrm{P}$-value greater than 0.05 indicates that there is no significant association between the variables, while any P-value less than 0.05 shows a significant association between the variables.

Table 14: Chi-Square Value for Age

\begin{tabular}{|c|c|c|c|c|}
\hline \multirow{2}{*}{ Quarter in 2018 } & \multicolumn{4}{|c|}{ Pearson Chi square } \\
\cline { 2 - 5 } & Value & Df & Asymp. Sig. (2-sided) & Level of Sig. \\
\hline Q1 & $45.808^{\mathrm{a}}$ & 7 & 0.001 & 0.05 \\
\hline Q2 & $64.137^{\mathrm{a}}$ & 7 & 0.001 & 0.05 \\
\hline Q3 & $30.834^{\mathrm{a}}$ & 7 & 0.001 & 0.05 \\
\hline Q4 & $26.217^{\mathrm{a}}$ & 7 & 0.001 & 0.05 \\
\hline
\end{tabular}

Source: LQAS 2018, Sokoto State 
Table 15: Chi-Square Value for Gender

\begin{tabular}{|c|c|c|c|c|}
\hline \multirow{2}{*}{ Quarter in 2018 } & \multicolumn{4}{|c|}{ Pearson Chi square } \\
\cline { 2 - 5 } & Value & Df & Asymp. Sig. (2-sided) & Level of Sig. \\
\hline Q1 & $0.233^{\mathrm{a}}$ & 1 & 0.629 & 0.05 \\
\hline Q2 & $2.346^{\mathrm{a}}$ & 1 & 0.126 & 0.05 \\
\hline Q3 & $0.082^{\mathrm{a}}$ & 1 & 0.775 & 0.05 \\
\hline Q4 & $3.718^{\mathrm{a}}$ & 1 & 0.054 & 0.05 \\
\hline
\end{tabular}

\section{Source: LQAS 2018, Sokoto State}

As contained below, hypotheses were tested for each quarter separately.

\section{Quarter 1 - Q1}

Hypothesis One:

$\mathrm{H}_{\mathrm{o}}$ : There is no significant association between the gender and immunization status of children.

$\mathrm{H}_{1}$ : There is a significant association between the gender and immunization status of children.

\begin{tabular}{|c|c|c|c|c|}
\hline \multicolumn{7}{|c|}{ Chi-Square Tests } \\
\hline Pearson Chi square & Value & Df & Asymp. Sig. (2-sided) & Level of Sig. \\
\hline & $.233^{\mathrm{a}}$ & 1 & .629 & 0.05 \\
\hline
\end{tabular}

Since the P-value (0.629) is greater than significant level (0.05), we accept $\mathrm{H}_{\mathrm{o}}$ and conclude that there is no significant association between the gender and immunization status of children.

Hypothesis Two:

$\mathrm{H}_{\mathrm{o}}$ : There is no significant association between the age and immunization status of children.

$\mathrm{H}_{1}$ : There is a significant association between the age and immunization status of children.

\begin{tabular}{|l|c|c|c|c|}
\hline \multicolumn{7}{|c|}{ Chi-Square Tests } \\
\hline \multirow{2}{*}{ Pearson Chi square } & Value & Df & Asymp. Sig. (2-sided) & Level of Sig. \\
\hline & $45.808^{\mathrm{a}}$ & 7 & .001 & 0.05 \\
\hline
\end{tabular}

Since the $\mathrm{P}$-value $(\mathrm{p} \leq 0.001)$ is less than significant level $(0.05)$, we accept $\mathrm{H}_{\mathrm{i}}$ and conclude that there is a significant association between the age and immunization status of children.

\section{Quarter 2 - Q2}

Hypothesis One:

$\mathrm{H}_{\mathrm{o}}$ : There is no significant association between the gender and immunization status of children.

$\mathrm{H}_{1}$ : There is a significant association between the gender and immunization status of children.

\begin{tabular}{|c|c|c|c|c|}
\hline \multicolumn{7}{|c|}{ Chi-Square Tests } \\
\hline Pearson Chi square & Value & Df & Asymp. Sig. (2-sided) & Level of Sig. \\
\hline & $2.346^{\mathrm{a}}$ & 1 & .126 & 0.05 \\
\hline
\end{tabular}

Since the P-value (0.126) is greater than significant level (0.05), we accept $\mathrm{H}_{\mathrm{o}}$ and conclude that there is no significant association between the gender and immunization status of children.

Hypothesis Two:

$\mathrm{H}_{\mathrm{o}}$ : There is no significant association between the age and immunization status of children.

$\mathrm{H}_{1}$ : There is a significant association between the age and immunization status of children. 


\section{Chi-Square Tests}

\begin{tabular}{|c|c|c|c|c|}
\hline Pearson Chi square & Value & Df & Asymp. Sig. (2-sided) & Level of Sig. \\
\hline & $64.137^{\mathrm{a}}$ & 7 & .001 & 0.05 \\
\hline
\end{tabular}

Since the P-value $(\mathrm{p} \leq 0.001)$ is less than significant level $(0.05)$, we accept $\mathrm{H}_{\mathrm{i}}$ and conclude that there is a significant association between the age and immunization status of children.

\section{Quarter 3 - Q3}

Hypothesis One:

$\mathrm{H}_{\mathrm{o}}$ : There is no significant association between the gender and immunization status of children.

$\mathrm{H}_{1}$ : There is a significant association between the gender and immunization status of children.

\begin{tabular}{|l|c|c|c|c|}
\hline \multicolumn{7}{|c|}{ Chi-Square Tests } \\
\hline Pearson Chi square & Value & Df & Asymp. Sig. (2-sided) & Level of Sig. \\
\hline & $.082^{\mathrm{a}}$ & 1 & .775 & 0.05 \\
\hline
\end{tabular}

Since the P-value (0.775) is greater than significant level (0.05), we accept $\mathrm{H}_{\mathrm{o}}$ and conclude that there is no significant association between the gender and immunization status of children.

Hypothesis Two:

$\mathrm{H}_{\mathrm{o}}$ : There is no significant association between the age and immunization status of children.

$\mathrm{H}_{1}$ : There is a significant association between the age and immunization status of children.

\begin{tabular}{|c|c|c|c|c|}
\hline \multicolumn{7}{|c|}{ Chi-Square Tests } \\
\hline Pearson Chi square & Value & Df & Asymp. Sig. (2-sided) & Level of Sig. \\
\hline & $30.834^{\mathrm{a}}$ & 7 & .001 & 0.05 \\
\hline
\end{tabular}

Since the $P$-value $(p \leq 0.001)$ is less than significant level $(0.05)$, we accept $H_{i}$ and conclude that there is a significant association between the age and immunization status of children.

\section{Quarter 4 - Q4}

Hypothesis One:

$\mathrm{H}_{\mathrm{o}}$ : There is no significant association between the gender and immunization status of children.

$\mathrm{H}_{1}$ : There is a significant association between the gender and immunization status of children.

\begin{tabular}{|l|c|c|c|c|}
\hline \multicolumn{7}{|c|}{ Chi-Square Tests } \\
\hline \multirow{2}{*}{ Pearson Chi square } & Value & Df & Asymp. Sig. (2-sided) & Level of Sig. \\
\hline & $3.718^{\mathrm{a}}$ & 1 & .054 & 0.05 \\
\hline
\end{tabular}

Since the P-value (0. 054) is greater than significant level $(0.05)$, we accept $\mathrm{H}_{\mathrm{o}}$ and conclude that there is no significant association between the gender and immunization status of children.

Hypothesis Two:

$\mathrm{H}_{\mathrm{o}}$ : There is no significant association between the age and immunization status of children.

$\mathrm{H}_{1}$ : There is a significant association between the age and immunization status of children.

\begin{tabular}{|l|c|c|c|c|}
\hline \multicolumn{7}{|c|}{ Chi-Square Tests } \\
\hline Pearson Chi square & Value & Df & Asymp. Sig. (2-sided) & Level of Sig. \\
\hline & $26.217^{\text {a }}$ & 7 & .001 & 0.05 \\
\hline
\end{tabular}


Since the $P$-value $(p \leq 0.001)$ is less than significant level (0.05), we accept $\mathrm{H}_{\mathrm{i}}$ and conclude that there is a significant association between the age and immunization status of children.

The result of the study shows that coverage of routine immunization is very low in Sokoto state. Although there is no notable difference in the coverage of male/female children, it is observed from the analysis that Dange-Shuni, Gwadabawa and Shagari LGAs had the highest number of children who have never being immunized and those with no immunization card.

Low level of routine immunization coverage in Sokoto state can be linked to the attitude of the caregivers. Most caregivers, whose children are partially/not immunized, stated that they are unable to take their children to health facility to receive vaccine. Additionally, some are not aware of the importance of routine immunization. This was observed from Q1 to Q4 of 2018.

Furthermore, the statistical test in the study establishes that there is a significant association between the age and immunization status of children. This association is inversely because as the age increases routine immunization coverage reduces.

Finally, in the aspect of hypotheses testing, over the periods of Q1 to Q4 in 2018, this study confirms that there is a significant association between the age and immunization status of children. Concerning the relationship between age and immunization coverage, the chi-square values $(\mathrm{p} \leq 0.001)$ in quarters 1,2,3 and 4 of 2018) are less than 0.05 which results in the acceptance of the assumption that there is a significant association between the age and immunization status of children.

On the other hand, regarding the relationship between gender and immunization coverage, the chi-square values (0.629, $0.126,0.775$ and 0.054 in quarters $1,2,3$ and 4 of 2018 respectively) are greater than 0.05 which results in the rejection of the assumption that there is a significant association between the gender and immunization status of children.

\subsection{CONCLUSION}

Findings from this research study has shown that routine immunization coverage is still very low in Sokoto State when compared with the national target of $80 \%$ coverage (RI Strategic Plan 2013-2015). The findings have clearly shown that the challenge of immunization coverage in Sokoto State is attributed to the following factors: Mothers/Caregivers inability to take their child to the health facility, unaware of immunization schedule, unaware of immunization need, absence of vaccinators, forgetfulness, no need felt, fear of AEFI, unaware of place and time, no faith/belief in immunization, lack of vaccines at the health facilities. The findings from this study were consistent with what Kabir M., et al., (2005) mentioned in his study on "Knowledge, perception and beliefs of mothers on routine childhood immunization in a Northern Nigerian Village" that religion, attitude and cultural believes of parent of children have been identified as some of the challenges why parents do not take their children for routine immunization services. This is also not far from a similar finding made by USAID on the status of routine immunization in northern Nigeria in the year 2018 which revealed that attitude; lack of education and awareness; culture and religion (USAID 2018) are the major challenges facing routine immunization in northern Nigeria. In a similar vein, a study by Gidado S., et al (2010) conducted in north west Nigeria on "Determinants of routine immunization coverage in Bungudu, Zamfara State, Northern Nigeria" found that mother's/caregiver's knowledge and educational status as among the major factors influencing immunization coverage in the region, (Saheed Gidado et al. 2014). Another finding of research work which is consistent with this research study conducted in Sokoto State in 2017 by Kaoje et. al. (2017), revealed that the socio-cultural factors affects the acceptance of routine immunization services by mothers/caregivers which includes place of delivery, educational level and the occupation of the parents of the children, (Kaoje et. al. 2017). Based on these findings, one can see clearly the consistencies between the findings of this research study and the previous research findings that were conducted previously.

The factors mentioned above are responsible for low immunization coverage in Sokoto State. It affects the percentage of fully immunized children in the state. The government and all stakeholders e.g. traditional and religious leaders, CSOs, NGOs should come together and ensure parents especially those leaving in the rural areas who are mostly uneducated and poor take their children for routine immunization because low immunization coverage will always pull back the effort of fighting vaccine preventable diseases.

\subsection{STRENGHT AND LIMITATION OF THE STUDY}

The major strength this research study has is the fact that the RI LQAS, 2018 secondary data used in this study is a complete representation of entire population of children under the age of one (0-11, months) of age precisely in Sokoto State. The enumeration area in this study cut across all the 23 LGAs, wards, communities and health facilities. In other to give an equal representation in this study, the sampling was randomized to give all the population of 0-11 months of age equal representation. Due to fear of misrepresentation of the population, the outcome of the entire study was generalized on the entire population of children 0-11 months old in the state. One of the major limitations from this research study is that the RI LQAS 2018 survey data used in the analysis did not capture statistics on socio demographic characteristics of the mothers/caregivers. This brought a limitation to number of analysis to be conducted on the survey data. As a result of the 
limitations "Age", "Gender" and "Immunization coverage" were used as independent variable for the inferential analysis conducted in this research study.

\subsection{RECOMMENDATION}

1. This study shows that about half of the children in Sokoto State, Nigeria are partially or not immunized. It is therefore suggested that government through the Sokoto State Primary Health Development agency should make an extra effort to sensitize caregivers and counseled them on the significance of taking their children to health facilities for vaccination till the later receive all necessary vaccines. The caregivers should be enlightened on the importance of each vaccine and be encouraged to attend health facility until their children are fully immunized according to immunization schedule.

2. Also, the study confirms that the ownership of immunization card, which is an important tool used to monitor the status of a child, is not $100 \%$. Caregivers should therefore be encouraged to collect and keep their children's immunization card appropriately.

3. Furthermore, Government should train RI Service Providers so that they can deliver their job effectively especially in the area of sensitization, EPI scheduling and to be present at work

4. On the part of the Non-Government Organization and other stakeholders, whenever there is an intervention program to address immunization coverage, all LGAs and communities in the State should be covered.

5. Government should work with traditional and religious leaders especially those at the rural part of the state so as to improve the uptake of vaccines.

\section{ACKNOWLEDGEMENT:}

To my darling wife Nafisa Muktar, my two lovely daughters Halima and Fatima and the Sokoto State Primary Health Care Development Agency (SSPHCDA) who gave me the permission to use the Sokoto State Routine Immunization Load Quality Assurance (RI LQAS) data.

\section{REFERENCES:}

Abdulraheem I. S et al. (2011), Reasons for incomplete vaccination and factors for missed opportunities among rural Nigerian children, online, available at: http://www.academicjournals.org/app/webroot/article/article137 9427155_Abdulraheem\%20et\%20al.pdf, Journal of Public Health and Epidemiology Vol. 3(4), [accessed 13/01/2020]

Adebiyi F. (2013), Determinants of full child immunization among 12-23 months old in Nigeria, online, available at: file:///C:/Users/User/Desktop/Module\%208\%20(Research\%20 Work)/MODULE-

8/Chapter\%20TWO/ADEBIYI\%20THESIS\%20-

\%20Very\%20Important.pdf, (accessed 01/01/2020).

Adedayo et al., (2009), Uptake Of Childhood Immunization Among Mothers Of Under-Five In Southwestern Nigeria, online, available at:

https://www.researchgate.net/profile/Olanrewaju_Oladimeji/pub lication/236904933 Uptake Of Childhood Immunization Am ong_Mothers_Of_Under-

Five_In_Southwestern_Nigeria/links/02e7e51a37df01e7890000 00/Uptake-Of-Childhood-Immunization-Among-Mothers-OfUnder-Five-In-Southwestern-Nigeria.pdf, The Internet Journal of Epidemiology, Google Scholar, [accessed 10/01/2020].

Adedire E. B., Ajayi K., Fawole O.I., Ajumobi, Kasasa S., Wasswa, P., (2016), Immunization coverage and its determinants among children aged 12-23 months in Atakumosawest district, Osun State Nigeria: a cross-sectional study, online, available at: https://link.springer.com/article/10.1186/s12889016-3531-x, (Accessed 16/11/2019)

Adedokun et al., (2017), Incomplete childhood immunization in Nigeria: a multilevel analysis of individual and contextual factors, online, available at:

https://bmcpublichealth.biomedcentral.com/articles/10.1186/s12 889-017-4137-7, BMC Public Health, (accessed 20/11/2019).

Adegboye O.A., et al., (2013), Multi-Year Trend Analysis of Childhood Immunization uptake and coverage in Nigeria, online, available at: https://www.cambridge.org/core/journals/journal-of-biosocialscience/article/multiyear-trend-analysis-of-childhoodimmunization-uptake-and-coverage-innigeria/EC948DCDF3C1C58FA9BD134D184BB6BA, [accessed 29/12/2019)

Alenoghena, I., et al. (2014), Primary Health Care in Nigeria: Strategies and Constraints in Implementation, online, available at:

https://www.ajol.info/index.php/ijcr/article/view/107665/97532, International Journal of Community Research, (accessed 26/12/2019)

Adeyinka D.A et al (2009), Uptake Of Childhood Immunization Among Mothers Of Under-Five In Southwestern Nigeria, online, available at: https://www.researchgate.net/profile/Olanrewaju_Oladimeji/pub lication/236904933_Uptake_Of_Childhood_Immunization_Am ong Mothers Of Under-

Five_In_Southwestern_Nigeria/links/02e7e51a37df01e7890000 00/Uptake-Of-Childhood-Immunization-Among-Mothers-OfUnder-Five-In-Southwestern-Nigeria.pdf, [accessed 17/02/2020]

Asrat Meleko et al. (2017), assessment of Child Immunization Coverage and Associated Factors with Full Vaccination among Children Aged 12-23 Months at Mizan Aman Town, Bench Maji Zone, Southwest Ethiopia, online, available at: https://www.hindawi.com/journals/ijpedi/2017/7976587/, International Journal of Pediatrics, Volume 2017, Article ID 7976587, [accessed 18/12/2019].

Brown V.B., Oluwatosin O. A., Ogundeji M.O (2017), Impact of training intervention on immunization providers' knowledge and practice of routine immunization in Ibadan, south-western Nigeria: a primary health care experience, online available at: https://www.panafrican-med-

journal.com/content/article/26/216/full/, [accessed 09/12/2019]

Caldwell, J. (1979). Education as a factor in mortality decline: An examination of Nigeria Data. Online, available at: https://www.scienceopen.com/document?vid=21ee9559-f87841fb-8f28-b5f8b759bc31 Journal of Population Studies, (accessed 07/01/2020). 
Dr. Faisal Shuaib (2017), NERICC-Nigeria's panacea to routine immunization and primary health care strengthening, online, available at: https://reliefweb.int/report/nigeria/nericc-nigeria-spanacea-routine-immunization-and-primary-health-carestrengthening, (accessed 10/11/2019).

D'Onofrio et al, (2010), Vaccine demand driven by vaccine side effects: dynamic implications for SIR diseases, online, available at: https://www.ncbi.nlm.nih.gov/pubmed/20149801, [accessed $11 / 01 / 2020]$.

Expanded Programme on Immunization (EPI), (1998). The Social Science and Immunization

Research project. Online, available at: https://www.ncbi.nlm.nih.gov/pubmed/9786041, Weekly Epidemiological Record, [accessed 25/02/2020]

Federal Ministry of Health Nigeria (FMOHN) (2004). Revised National Health Policy. Abuja: Federal Ministry of Health, online, available at: https://cheld.org/wpcontent/uploads/2012/04/Nigeria-Revised-National-HealthPolicy-2004.pdf, (accessed 27/12/2019).

Funmilayo Adebiyi (2013), Determinants of Full Child Immunization among 12-23 months old in Nigeria, online, available at:

file:///C:/Users/User/Desktop/Module\%208\%20(Research\%20

Work)/MODULE-

8/Chapter\%20TWO/ADEBIYI\%20THESIS\%20-

\%20Very\%20Important.pdf, [accessed 12/02/2020]

Gauri V., et al. (2002), Immunization in developing countries: its political and organizational determinants, World

Development, online, available at:

http://documents.worldbank.org/curated/en/7059614687394893

36/pdf/multi0page.pdf2002, (accessed 01/01/2020).

Global Vaccine Action Plan 2011-2020, online, available at: https://www.who.int/immunization/global_vaccine_action_plan/ GVAP_doc_2011_2020/en/, Google Scholar, [accessed 02/01/2020]

Harvey, P.A.M. (2014) Factors Influencing Vaccination in Nigeria, online, available at:

http://gradworks.umi.com/34/44/3444115.html, (accessed 10/01/2020)

Jegede AS (2007), What Led to the Nigerian Boycott of the Polio Vaccination Campaign?, online, available at: https://journals.plos.org/plosmedicine/article?id=10.1371/journa 1.pmed.0040073, Google Scholar, accessed 05/01/2020

Jheeta M., et al, (2008), Childhood vaccination in Africa and Asia: the effects of parents' knowledge and attitudes, online available at: https://www.ncbi.nlm.nih.gov/pubmed/18568264, Journal of social science Medicine, [accessed 07/01/2020)

Kabir M. et al., Knowledge, perception and beliefs of mothers on routine childhood immunization in a Northern Nigerian Village, online, available at:

https://www.ajol.info/index.php/anmed/article/view/38319,

Annals of Nigerian Medicine Vol. 1(1) 2005: 21-26, (accessed $15 / 11 / 2019)$

Kaoje A.U. et al., (2017), Prevalence of vaccine preventable diseases and utilization of routine immunizations services by parents of under-one children in a semi-urban community of Sokoto State, Nigeria, online, available at:
http://www.gjmedph.com/uploads/O5-Vo6No4.pdf, Global Journal of Medicine and Public Health, [accessed 12/12/2019]

LaFond A., et al 2015), Drivers of routine immunization coverage improvement in Africa: findings from district-level case studies, online, available at: https://academic.oup.com/heapol/article/30/3/298/616144, Health Policy and Planning, (accessed 01/12/2019).

Lee, S. (2005). Demand for immunization, parental selection and child survival: Evidence from rural India, online, available at: https://link.springer.com/article/10.1007/s11150-005-0709-x, Review of Economics of the Household, Google Scholar, [accessed 13/01/2020].

Levin, K.A., (2006), Study design III: Cross-sectional studies, online, 2006, available at:

https://www.nature.com/articles/6400375, [accessed 03/11/2019]

Lorraine K. Alexander L.K., Lopes B., Masterson R., Yeatts K.B., (2014), Eric Notebook, Cross-sectional Studies, second edition, UNC CH Department of Epidemiology, pp3 Machingaidze S., (2013), Strengthening the Expanded Programme on Immunization in Africa: Looking beyond 2015, online, available at:

https://journals.plos.org/plosmedicine/article?id=10.1371/journa l.pmed.1001405, Google Scholar, (accessed 05/05/2020)

Mihigo R., et al., (2017), Challenges of immunization in the African Region, online, available at: http://www.panafricanmed-journal.com/content/series/27/3/12/full/, (accessed $07 / 12 / 2019)$

Multiple Indicator Cluster Survey 2016-17, Survey Finding Report, pp. v

Mutua, M., Kimani-Murage, E., \& Ettarh, R. (2011). Childhood vaccination in informal urban settlements in Nairobi, Kenya: Who gets vaccinated?, online available at:

https://bmcpublichealth.biomedcentral.com/articles/10.1186/147 1-2458-11-6, Biomedical Central Public Health, [accessed $15 / 01 / 2020]$

Ndiritu, M., Cowgill, K., Ismail, A., Chiphatsi, S., \& Kamau, T. (2006). Immunization coverage and risk factors for failure to immunize within the Expanded programme of immunization in Kenya after the introduction of Hemophilus influenza type $b$ and hepatitis b virus antigens, online, available at: https://www.ncbi.nlm.nih.gov/pubmed/1670701, Biomedical Central Public Health , (accessed 05/01/2020).

Ngowu, R., Larson, J. R., \& Kim, M. S. et al. (2008). Reducing child mortality in Nigeria: A case study of immunization and systemic factors, online, available at:

https://scholar.google.com/scholar?hl=en\&q=+Reducing+child+ mortality+in+Nigeria:+a+case+study+of+immunization+and+sy stemic+factors, Social Science and Medicine, Google Scholar, [accessed 12/12/2019].

NIC Survey Brief (2017), online, available at: National Immunization Coverage Survey (NICS): National Brief https://www.jhsph.edu/ivac/wpcontent/uploads/2018/04/Nigeria-NICS-National-Brief.pdf, [accessed 25/02/2020].

Nigerian National Routine Immunization Strategic Plan(20132015), online, available at: http://www.nationalplanningcycles.org/sites/default/files/countr 
ע_docs/Nigeria/ri_strategic_plan_combined_mahmud_draft_1.p df, [accessed 11/11/2019].

NPoPC, National Population Commission of Nigeria, online available at:

https://www.google.com/search?q=national+population+commi ssion+of+nigeria+(web)\&rlz=1C1GGRV_enNG874NG874\&oq =National+population+commission+of+N\&aqs=chrome.2.0j69i $\underline{57 j 016.19609 j 0 j 7 \& \text { sourceid }=\text { chrome } \& i e=U T F-8}$, [accessed $19 / 11 / 2019]$

Odusanya O., Alufohai, E.F., Meurice F., Ahonkhai V.I, (2008), Determinants of vaccination coverage in rural Nigeria, online, available at:

https://bmcpublichealth.biomedcentral.com/articles/10.1186/147 1-2458-8-381, (accessed 15/11/2019).

Oluwadare C., (2017), The Social Determinants of Routine Immunization in Ekiti State of Nigeria, online, available at: https://www.tandfonline.com/doi/abs/10.1080/09735070.2009.1 1886337, [accessed 02/12/2019]

Oku A., et al, (2017), Factors affecting the implementation of childhood vaccination communication strategies in Nigeria: a qualitative study, online, available at:

https://bmcpublichealth.biomedcentral.com/articles/10.1186/s12 889-017-4020-6, BMC Public Health, [accessed 03/01/2020]

Omoleke et al (2017), A pilot study of routine immunization data quality in Bunza Local Government area: causes and possible remedies, online, available at: https://www.panafricanmed-journal.com/content/article/27/239/full/, The Pan African Medical Journal,(accessed 13/11/2019).

Ophori E.A. et al., (2014), Current Trends of Immunization in Nigeria: Prospect and Challenges, online, available at: https://www.ncbi.nlm.nih.gov/pmc/articles/PMC4139536/, [accessed 25/02/2020]

Owoseye A., (2018), 2017: Sad year in Nigeria's health sector; over 1,000 die from preventable diseases, online, available at: https://www.premiumtimesng.com/news/headlines/2541272017-sad-year-in-nigerias-health-sector-over-1000-die-frompreventable-diseases.html, [accessed 12/02/2019]

Reichler, R., Darwish, A., Stroh, G., Stevenson, J., Al Nasar, M., \& Oun, S. (1998). Cluster survey evaluation of coverage and risk factors for failure to be immunized during the 1995

National Immunization Days in Egypt, online, available at: https://watermark.silverchair.com/27-6-

1083.pdf?token=AQECAHi208BE49Ooan9kkhW, Internal Journal of Epidemiology, (accessed 04/01/2020).

Rhoda A., et al., (2010), LQAS: User Beware, online, available at: https://academic.oup.com/ije/article/39/1/60/709971, International Journal of Epidemiology, Volume 39, Issue 1, February 2010, Pages 60-68, [Accessed 03/12/2019].

Saheed Gidado et al. (2014), Determinants of routine immunization coverage in Bungudu, Zamfara State, Northern Nigeria, online, available at:

https://www.researchgate.net/publication/267097984_Determina nts of routine immunization coverage in Bungudu Zamfara State_Northern_Nigeria_May_2010, [accessed 11/11/2019]

Salako A.A et al., (2009), An Appraisal of Immunization in Nigeria: Towards Improving Coverage, online, available at: https://www.ajol.info/index.php/nhp/article/view/45414, Journal

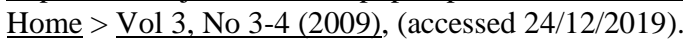

Saleena et al., (2014), Global Routine Vaccination Coverage, 2014, online, available at:

https://www.cdc.gov/mmwr/preview/mmwrhtml/mm6444a5.ht $\underline{\text { m, }}$ [accessed 25/02/2020]

Sule Abdullahi (2018), Factors Affecting Completion of Childhood Immunization in North West Nigeria, online, available at:

https://scholarworks.waldenu.edu/cgi/viewcontent.cgi?article=7 095\&context=dissertations, [accessed 12/02/2020]

Tagbo, B.N., Uleanya, N.D. and Omotowo, I.B. (2013), Mothers' Perception of Adverse Events Following Routine Immunization, online, available at:

https://www.researchgate.net/publication/267154893 Mothers' Knowledge_and_Perception_of_Adverse_Events_Following_Im munization_in_Enugu_South-East_Nigeria, Journal of Vaccines \& Vaccination, (accessed 10/01/2020)

The Millennium Development Goals Report (2015), online, available at:

https://www.un.org/millenniumgoals/2015_MDG_Report/pdf/ba ckgrounders/MDG\%202015\%20PR\%20Bg\%20SSA.pdf, (accessed 29/12/2019).

UNICEF (2008), Joint Press Release, online, available at: https://www.unicef.org/media/media_46751.html, [accessed $18 / 02 / 2020]$

UNICEF 2018, Immunization programme, online, available at: https://www.unicef.org/immunization, (accessed 06/11/2019).

USAID 2018, Strengthening Routine Immunization through Subnational Partnerships - The Experience in Sokoto State, Nigeria, online, available at:

https://www.mcsprogram.org/resource/strengthening-routineimmunization-through-subnational-partnerships-the-experiencein-sokoto-state-nigeria/, [accessed 17/11/2019].

WHO 2015, Vaccine preventable deaths and the Global Immunization Vision and Strategy, 2006-2015, online, available at: https://www.ncbi.nlm.nih.gov/pubmed/16691182, Geneva, Switzerland and New York, USA., (accessed 10/10/2019).

WHO (2017), Immunization Progress Report, online, available at: https://stamen.com/work/who-immunization-2017/, [accessed 08/11/2019]?

Wiysonge C. S. et. al, (2012), Advances in childhood Immunization in South Africa: Where to now? Programme manager's views and evidence from systematic reviews, online available at:

https://www.researchgate.net/publication/230591264_Advances _in_childhood_immunisation_in_South_Africa_Where_to_now _Programme_managers_views_and_evidence_from_systematic _reviews, BMC Public Health, [accessed 13/12/2019]. 